\title{
Absence of Functional Peroxisomes from Mouse CNS Causes Dysmyelination and Axon Degeneration
}

\author{
Leen Hulshagen, ${ }^{1}$ Olga Krysko, ${ }^{1}$ Astrid Bottelbergs, ${ }^{1}$ Steven Huyghe, ${ }^{1}$ Rüdiger Klein, ${ }^{5}$ Paul P. Van Veldhoven, ${ }^{2}$ \\ Peter P. De Deyn, ${ }^{6}$ Rudi D’Hooge, ${ }^{6}$ Dieter Hartmann, ${ }^{3,4,7}$ and Myriam Baes ${ }^{1}$ \\ ${ }^{1}$ Laboratory of Cell Metabolism, Department of Pharmaceutical Sciences, ${ }^{2}$ Laboratory for Lipid Biochemistry and Protein Interactions, Department of \\ Molecular Cell Biology, and ${ }^{3}$ Center for Human Genetics, Katholieke Universiteit Leuven, and ${ }^{4}$ Department of Molecular and Developmental Genetics, \\ Flanders Institute for Biotechnology, B-3000 Leuven, Belgium, ${ }^{5}$ Max-Planck-Institut für Neurobiologie, D-82152 Martinsried, Germany, ${ }^{6}$ Laboratory of \\ Neurochemistry and Behaviour, University of Antwerp, B-2610 Antwerp, Belgium, and 'Department of Anatomy, University of Bonn, D-53115 Bonn, \\ Germany
}

Peroxisomal metabolism is essential for normal brain development both in men and in mice. Using conditional knock-out mice, we recently showed that peroxisome deficiency in liver has a severe and persistent impact on the formation of cortex and cerebellum, whereas absence of functional peroxisomes from the CNS only causes developmental delays without obvious alteration of brain architecture.

We now report that a substantial fraction of the latter Nes-Pex5 knock-out mice survive into adulthood but develop progressive motoric and coordination problems, impaired exploration, and a deficit in cognition and die before the age of 6 months. Histopathologically, both the white and gray matter of the CNS displayed a region-specific accumulation of neutral lipids, astrogliosis and microgliosis, upregulation of catalase, and scattered cell death. Nes-Pex 5 knock-out mice featured a dramatic reduction of myelin staining in corpus callosum, whereas cerebellum and other white matter tracts were less affected or unchanged. This was accompanied by a depletion of alkenylphospholipids in myelin and differentially reduced immunoreactivity of myelin proteins. EM analysis revealed that myelin wrappings around axons did still form, but they showed a reduction in thickness relative to axon diameters. Remarkably, multifocal axonal damage occurred in the corpus callosum. Thereby, debris accumulated between axolemma and inner myelin surface and axons collapsed, although myelin sheaths remained present. These anomalies of myelinated axons were already present in juvenile mice but aggravated in adulthood. Together, loss of CNS peroxisomal metabolism both affects myelin sheaths and axonal integrity possibly via independent pathways.

Key words: peroxisome; myelin; Zellweger syndrome; plasmalogen; fatty acid; knock-out mice; astrocyte; axon; microglia

\section{Introduction}

Peroxisomes fulfill multiple tasks in metabolism and adapt contents and functions according to cell type, age, and organism. Among the metabolic reactions that take place in peroxisomes, oxygen metabolism, $\beta$-oxidation of a number of carboxylates that cannot be handled by mitochondria, $\alpha$-oxidation of 3-methyl branched chain and 2-hydroxy fatty acids, ether lipid synthesis, and detoxification of glyoxylate are the most important (Mannaerts and Van Veldhoven, 1993; Wanders and Waterham, 2006).

Received June 19, 2007; revised Feb. 6, 2008; accepted Feb. 18, 2008.

This work was supported by grants from Fonds Wetenschappelijk Onderzoek Vlaanderen (G.0235.01 and G.0385.05), Geconcerteerde Onderzoeksacties (2004/08), the European Union ("MMPD," QLG1-CT2001-01277, FP5; "Peroxisomes," LSHG-CT-2004-512018, FP6), and the European Leukodystrophy Association (2007-00414). The excellent technical help of Benno Das, Lies Pauwels, Els Meyhi, Sven Terclavers, Nico Smets, Birgit Rau, Bärbel Balzer Ulrike Schwaab, Elke Maes, An Snellinx, Koen Poesen, and An Verheyen is gratefully acknowledged.

Correspondence should be addressed to Prof. Dr. Myriam Baes, Laboratory of Cell Metabolism, Department of Pharmaceutical Sciences, Herestraat 49 0/N Box 823, B-3000 Leuven, Belgium. E-mail: myriam.baes@ pharm.kuleuven.be.

R. D'Hooge's present address: Laboratory of Biological Psychology, Department of Psychology, Katholieke Universiteit Leuven, B-3000 Leuven, Belgium.

D01:10.1523/JNEUROSCI.4968-07.2008

Copyright $\odot 2008$ Society for Neuroscience $\quad$ 0270-6474/08/284015-13\$15.00/0
Loss or impairment of peroxisomal function, as seen in peroxisome biogenesis disorders, or mutations of individual peroxisomal enzymes or transporter proteins result in characteristic patterns of CNS lesions (Powers and Moser, 1998).

First, the most severe peroxisome biogenesis disorder, Zellweger syndrome, and some single peroxisomal $\beta$-oxidation enzyme deficiencies cause cytoarchitectonic abnormalities including cortical neuronal migration defects, malformations of the cerebellum and of the inferior medullary olives (Evrard et al., 1978; Gould et al., 2001). These defects were recapitulated in Zellweger mouse models (Baes and Van Veldhoven, 2006). Second, disturbed function of peroxisomes is associated with white matter anomalies that can be both demyelinative and dysmyelinative in nature (Powers and Moser, 1998). Finally, peroxisomal disorders are linked with neuronal degenerations, including degeneration and loss of Purkinje and granule cells (Powers et al., 1999; Bams-Mengerink et al., 2006), lesions in the spinal cord (Kumar et al., 1995; Powers et al., 2000), and loss of sensory neurons (Wanders et al., 2001). Although in some cases the neuropathologic alterations are associated with specific metabolic perturbations, no causal links have been experimentally proven 
and the pathomechanisms of the neurological abnormalities remain unresolved.

Analysis of peroxisome function in brain development and maintenance is further complicated by our still poor knowledge of peroxisome distribution by brain region, cell type(s), and developmental kinetics. Initial electron microscopical studies (Arnold and Holtzman, 1978; Holtzman, 1982) using cytochemical visualization of catalase (and thus perhaps not revealing all peroxisomes) reported microperoxisomes for all cell types, with a preponderance for glial cells and early postnatal stages, but their absence from several adult brain regions. Peroxisomes were abundant in oligodendrocytes during myelination (Adamo et al., 1986). More recent immunohistochemical data indicated constant brain expression of peroxisomal proteins from the juvenile period into adulthood (Adamo et al., 1986; Imamura et al., 1994; Itoh et al., 1999, 2000; Huyghe et al., 2001; Ahlemeyer et al., 2007).

Recent data from our own group indicate that the role of peroxisomes for CNS development may not only depend on their presence and dynamics in neurons and glial cells. Indeed, we showed that elimination of functional peroxisomes from fetal liver, by $\alpha$-fetoprotein promoter driven Cre recombination of the Pex5 gene, had a dramatic and permanent impact on the formation of cortex and cerebellum. In contrast, local ablation of Pex5 from the CNS using Nestin-Cre mice, only caused delays in neuronal positioning during the prenatal and early postnatal period (Krysko et al., 2007). Because a substantial fraction of the NesPex5 knock-out mice survived into early adulthood, we have further exploited this model to investigate the long-term effects of a complete deficiency of functional peroxisomes within the CNS.

\section{Materials and Methods}

\section{Animals}

Nestin-Cre (Nes-Cre) mice (Tronche et al., 1999) were mated with Pex $5^{F L /+}$ mice (Baes et al., 2002), and selected Nes-Cre Pex $5^{F L /+}$ offspring were crossed with Pex $5^{F L / F L}$ mice to obtain Nes-Cre Pex5 $5^{F L / F L}$, further denoted as Nes-Pex5 knock-out mice (Krysko et al., 2007).

Twenty-five percent of the pups born from Nes-Cre Pex $5^{F L /+}$ and $P e x 5^{F L / F L}$ parents were Cre-positive and homozygous for the floxed Pex 5 allele as expected for Mendelian inheritance of the alleles. Littermates with one of the other possible genotypes were considered as control mice. Mice were bred under conventional conditions, a $12 \mathrm{~h}$ light/dark cycle with standard rodent food chow and water ad libitum. All animal experiments were approved by the Institutional Animal Ethical Committee of the University of Leuven.

Genotypes were determined on tail DNA via PCR analysis using the Cre primers (5'-GCCTGCATTACCGGTCGATGCAACGA and 5'GTGGCAGATGGCGCGGCAACACCATT) and two Pex5 primers encompassing a DNA fragment containing the $3^{\prime}$-loxP site (5'-CTCTGGTTCCCATTGGCCAGGGTGG and 5'-GGGGAGTACGACAAGGCTGTGGACTG), to distinguish a shorter wild-type band and a longer loxP-containing band.

\section{Biochemical analysis}

Nes-Pex 5 knock-out and control mice were anesthetized with an overdose of Nembutal (150 $\mu \mathrm{g} / \mathrm{g}$ body weight). Brains were removed, and cerebella and cerebra were separated, sagitally cut, snap frozen in liquid nitrogen, and stored at $-80^{\circ} \mathrm{C}$.

RNA isolation and quantitative PCR. RNA was isolated from cerebellum using the Trizol reagent (Invitrogen, Merelbeke, Belgium) and reverse transcribed with Superscript II Reverse Transcriptase (Invitrogen). Quantitative PCRs were then performed by using an ABI Prism 7700 (Gene-Amp PCR system 9600; Applied Biosystems, Foster City, CA) and the TaqMan system.

Primers and probes for calbindinD- ${ }_{28 \mathrm{~K}}$ [ forward primer, $5^{\prime}$-AACTGACAGAGATGGCCAGGTTA (603-625); probe, $5^{\prime}$-ACCAGTG-
CAGGAAAATTTCCTTCTTAAATTCCA (628-660); and reverse primer, 5'-TGAACTCTTTCCCACACATTTTGAT (665-689)] and HPRT [forward primer, 5'-TTATCAGACTGAAGAGCTACTGTAATGATC (383-412); probe, 5'-TGAGAGATCATCTCCACCAATAACTTTTATGTCCC (422-456); and reverse primer 5'-TTACCAGTGTCAATTATATCTTCAACAATC (480-509)], and catalase [forward primer, 5'-CGCAGAGACCTGATGTCCTGA (145-164); probe, 5'CACCGGAGGCGGGAACCCAATA (166-185); and reverse primer, 5' CCCCGCGGTCATGAATATTAA (205-223)] were designed by using the program Primer Express (Applied Biosystems) and were purchased from GE Healthcare (Diegem, Belgium), Sigma-Aldrich (St. Louis, MO), and Eurogentec (Seraing, Belgium). The relative expression level of the target gene calbindinD- ${ }_{28 \mathrm{~K}}$ and catalase was calculated as a ratio to the housekeeping gene HPRT.

Western blot analysis. After homogenizing cerebrum, cerebellum, or microdissected corpus callosum in $0.25 \mathrm{~m}$ sucrose, $5 \mathrm{~mm}$ MOPS, and 1 mм EDTA, $30 \mu \mathrm{g}$ of proteins were separated by $10 \%$ SDS-PAGE [ $12 \%$ for myelin basic protein (MBP)]. The monoclonal antibodies glial fibrillary acidic protein (GFAP), proteolipid protein (PLP) (Millipore Bioscience Research Reagents, Temecula, CA), and the polyclonal rabbit antibodies to MBP (Millipore Bioscience Research Reagents) and catalase (Rockland Immunochemicals, Gilbertsville, PA) were used. The monoclonal antibody myelin-associated glycoprotein (MAG) (Millipore Bioscience Research Reagents) was used under nonreducing conditions.

Lipid analysis. Total lipid extracts were processed for fatty acid analysis as previously described (Baes et al., 1997). For plasmalogen analysis, aliquots of dried lipid extracts were dissolved in $200 \mu \mathrm{l}$ of $10 \mathrm{~mm}$ dinitrophenylhydrazine (in ethanol/1 $1 \mathrm{~N} \mathrm{H}_{2} \mathrm{SO}_{4}, 1 / 1, \mathrm{v} / \mathrm{v}$ ) and placed at $50^{\circ} \mathrm{C}$ for $30 \mathrm{~min}$. After adding water, hydrazones were extracted into hexane, dried shielded from light, and dissolved in $100 \mu \mathrm{l}$ of acetonitrile of which $50 \mu \mathrm{l}$ was injected on a C18-Symmetry column $(5 \mu \mathrm{m} ; 100 \AA$; $4.6 \times 150 \mathrm{~mm}$; Waters, Milford, MA) run in acetonitrile at $0.8 \mathrm{ml} / \mathrm{min}$ and monitored at $360 \mathrm{~nm}$ as described previously (Foulon et al., 2005). For calculation, the areas corresponding to the eluted nitrophenylhydrazone derivatives of hexadecanal, octadecanal, and octadecenal were summed up and compared with an external standard (gravimetric solution of hexadecanal dimethyl acetal). Triglycerides, cholesterol, and cholesterylesters were isolated by thin-layer chromatography and analyzed with coupled enzymatic assays as described previously (Van Veldhoven et al., 1997, 1998; Huyghe et al., 2006a) except for cholesterylesters and triglycerides that were hydrolyzed chemically $\left(5 \% 5 \mathrm{M} \mathrm{KOH}\right.$ in ethanol; $75^{\circ} \mathrm{C}$; $\left.90 \mathrm{~min}\right)$. Statistical analysis was done by unpaired Student's $t$ test.

\section{Isolation of myelin}

Myelin was isolated according to Kwik-Uribe et al. (2000), and the lipid content was further analyzed as described for cerebrum.

\section{Behavioral studies}

Behavioral performance was assessed repeatedly in 16 Nes-Pex5 knockout and 16 control mice between 7 and 19 weeks of age, as described previously (D'Hooge et al., 2001; Caeyenberghs et al., 2006; Goddyn et al., 2006). Neuromotor tests included rotarod, wire suspension, and cage activity. The rotarod test comprised a 2 min adaptation trial $(4 \mathrm{rpm})$ and four test trials on an accelerating rotarod apparatus (4-40 rpm in $5 \mathrm{~min}$; Ugo Basile, Comerio, Italy). In the wire suspension test, mice were put on a horizontal wire $(0.6 \mathrm{~mm}$ thick) that was suspended $46 \mathrm{~cm}$ above table top. Mice were held in front of the wire and allowed to grab it with their front paws while being slightly held by their tail ( $120 \mathrm{~s}$ trial). Cage activity was recorded in single-housed mice during $23 \mathrm{~h}$ using infrared photocells and a laboratory-built beam interruption counter. Exploration tests included open-field and dark/light transition recordings. Open-field exploration was assessed in a $50 \times 50 \mathrm{~cm}^{2}$ brightly lit arena during the dark phase of their activity cycle. After 1 min adaptation, exploratory activity was video tracked for 10 min (Chromotrack; San Diego Instruments, San Diego, CA). The dark/light transition box consisted of a small dark and (4.5 times) larger illuminated chamber. Mice were placed in the dark side, and the number of transitions between the compartments was registered for $10 \mathrm{~min}$ with infrared photocells. Passive avoidance learning was measured in a step-through box. The avoidance learning procedure 
does not allow repeated testing and was therefore only performed at 11 weeks of age. During the dark phase of their cycle, mice were put in the illuminated compartment, a door leading to the dark compartment was opened after $5 \mathrm{~s}$, and the mice received a brief footshock $(0.3 \mathrm{~mA} ; 1 \mathrm{~s})$ on entry. Twenty-four hours later followed a test trial that allowed reassessment of step-through latency (up to $300 \mathrm{~s}$ ).

\section{Measurement of compound motor action potentials}

For electrophysiological recordings, 5-month-old animals were anesthetized with Nembutal ( $70 \mu \mathrm{g} / \mathrm{g}$ body weight). The stimulating electrodes were inserted at the hip near the sciatic nerve (active electrode) and in base of the tail (reference electrode). The detection electrodes were inserted in the gastrocnemius muscle (active electrode), under the skin of vertebral column (grounding), and in the Achilles tendon (reference electrode). After stimulation of the sciatic nerve, the velocity of nerve conduction to the gastrocnemius muscle was analyzed. This was done by measuring the amplitude (in microvolts) and latency (in milliseconds) of the recorded patterns of motor unit action potentials.

\section{Histological analysis}

Three to five Nes-Pex5 knock-out and control mice at an age of 3, 6, 12, and 20 weeks were anesthetized with an overdose of Nembutal $(150 \mu \mathrm{g} / \mathrm{g}$ body weight) and intracardially perfused with $10 \%$ neutral buffered formalin (Prosan, Merelbeke, Belgium).

The brain and vertebral column were removed from the animal, postfixed overnight in the same fixative, and embedded in paraffin.

Immunohistochemical analysis. Five-micrometer-thick sections were processed as previously described (Huyghe et al., 2006b) except that, depending on the antibody, trypsinization or heating of tissues in citrate buffer was applied for antigen retrieval. The following primary antibodies were used: monoclonal mouse antibodies against GFAP (SigmaAldrich), PLP (Millipore Bioscience Research Reagents), nonphosphorylated neurofilament SMI32 (Sternberger, Baltimore, MD), amyloid precursor protein (APP) (Millipore Bioscience Research Reagents), cleaved caspase-3 (Cell Signaling Technology, Danvers, MA), CC1 (Calbiochem, San Diego, CA), CD45 (BD Pharmingen, San Diego, CA), $2^{\prime}, 3^{\prime}$-cyclic nucleotide $3^{\prime}$-phosphodiesterase (CNP) (Sternberger); monoclonal rat antibody against F4/80 (Serotec, Oxford, UK), and polyclonal rabbit antibodies against CD3 (BD Pharmingen), MBP, and catalase already described for Western blot analysis. The secondary antibodies were conjugated with peroxidase (horse anti-mouse IgGs; Vector Laboratories, Burlingame, CA; goat anti-rabbit IgGs, Dako, High Wycombe, UK) or biotin (rabbit anti-rat IgGs; Vector Laboratories). Tyramide conjugated fluorochromes were used for detection with the tyramide signal amplification kits (PerkinElmer Life and Analytical Sciences, Waltham, MA). Sections were coverslipped with Vectashield (Vector Laboratories) and images were obtained by fluorescence microscopy [Carl Zeiss (Jena, Germany) Axioplan 2 Imaging equipped with a Carl Zeiss AxioCam HRc camera and a Nikon (Tokyo, Japan) 90i microscope with a Nikon DM 1200 camera].

When double stainings were performed, antibodies were added consecutively and the cyanine 3 amplification kit TSA (PerkinElmer Life and Analytical Sciences) was used for amplification.

For determining the density of oligodendrocytes in the corpus callosum, sections from comparable anatomical regions were stained with CC1 antibody and counterstained with DAPI (4', $6^{\prime}$-diamidino-2phenylindole). To avoid regional and experimental variations in labeling, sections from control and knock-out mice were treated simultaneously. For each mouse, cells were counted in three different fields.

Five-micrometer-thick cryostat sections of fresh frozen brain were fixed in ice-cold pure acetone and stained according to the procedure described above. Antibodies for MAG (Millipore Bioscience Research Reagents) were diluted 1/1000, and antibodies for MBP and CNP were diluted 1/5000.

Luxol fast blue staining. Myelin was detected using the Luxol fast blue (LFB) stain (Solvent Blue 38; Sigma-Aldrich). Sections were deparaffinized and incubated overnight at $56^{\circ} \mathrm{C}$ in $0.1 \% \mathrm{LFB}$ solution. The next day, slides were cooled at $4^{\circ} \mathrm{C}$ and stained sections were then differentiated in $\mathrm{Li}_{2} \mathrm{CO}_{3}$ for $5 \mathrm{~min}$ and briefly in $70 \%$ ethanol, followed by a

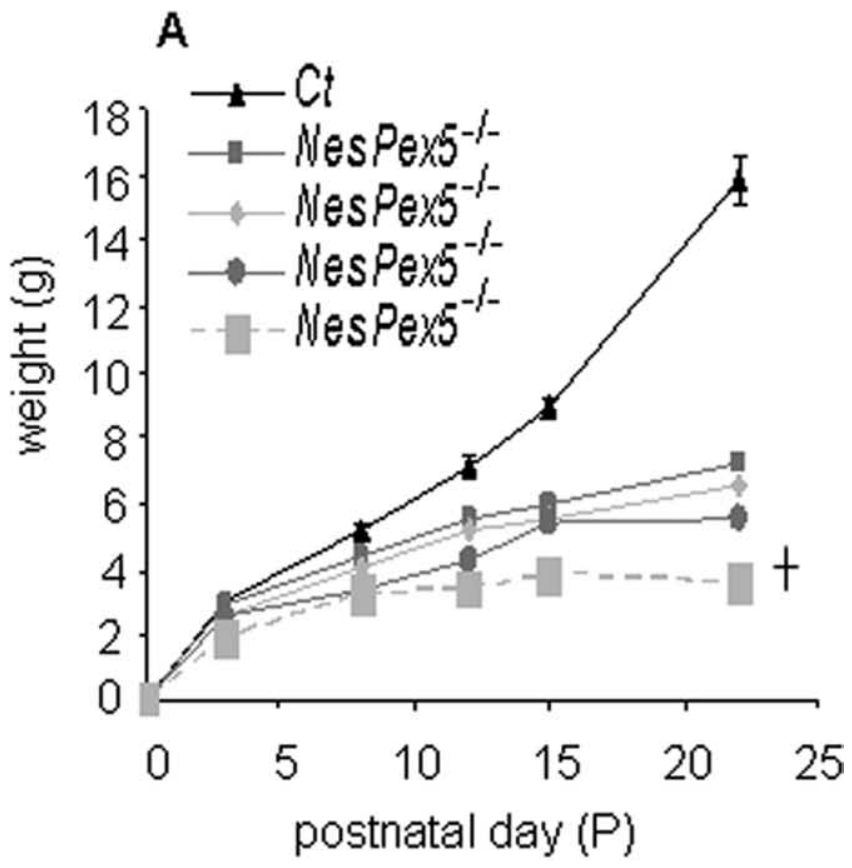

B

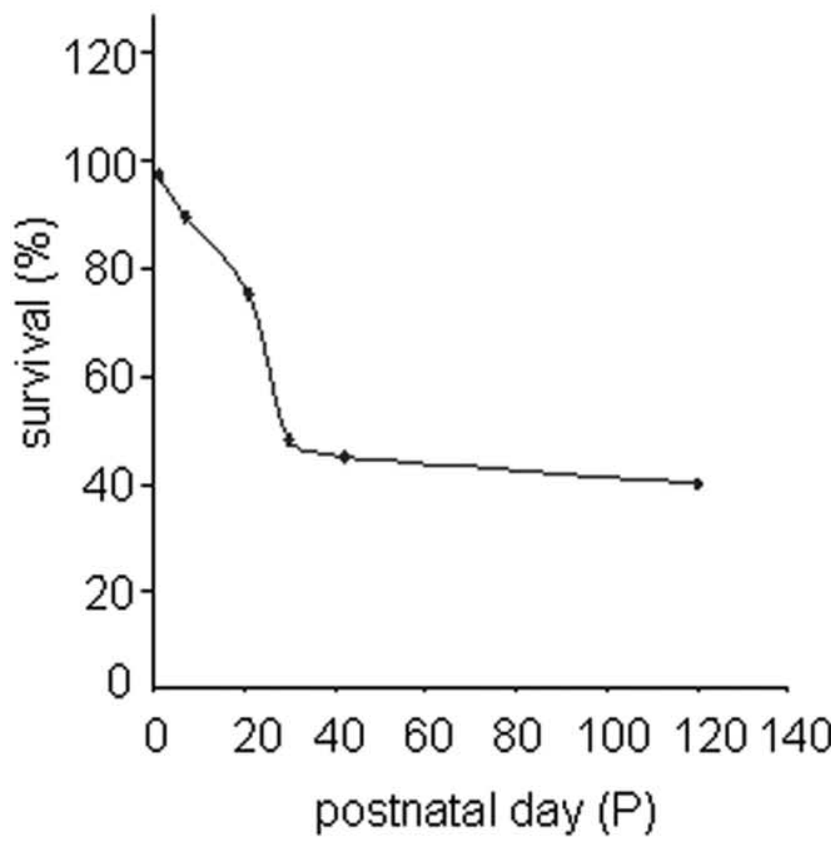

Figure 1. Retarded growth of Nes-Pex5 knock-out mice. A, Typical growth curve of Nes-Pex5 knock-out ( 4 individual mice) and control mice (triangles, mean \pm SEM of 4 mice) born from the same litter. A marked growth retardation with variable onset between day 3 and 7 could be observed. The most growth-retarded knock-out mouse died after weaning. $\boldsymbol{B}$, Survival curve of Nes-Pex 5 knock-out mice. 0 f 63 Nes-Pex 5 knock-out mice, $57 \%$ died within 6 weeks of age, with a peak between postnatal days 21 and 30 .

counterstaining with Nuclear Fast Red. Dehydration was performed in graded alcohol baths and xylene and sections were coverslipped with DPX (Prosan). Care was taken to process knock-out samples with their respective controls in parallel.

Visualization of lipids. Five-micrometer-thick cryostat sections were stained with the lipid-soluble dye Oil Red O (color index no. 26125; BDH Laboratory Supplies, Poole, UK) $0.24 \% \mathrm{w} / \mathrm{v}$ in isopropanol/water (3:2) for $18 \mathrm{~min}$. Sections were mounted with glycerol-gelatin solution. 
Electron microscopical analysis

At least two mice of each genotype were anesthetized with an overdose of Nembutal and perfused with $6 \%$ glutaraldehyde in Sörensen buffer at $\mathrm{pH}$ 7.2. Tissues were postfixed for $24 \mathrm{~h}$ in $6 \%$ glutaraldehyde, osmicated, and embedded in glycidether (Serva, Heidelberg, Germany). Semithin sections used for light microscopy were stained with $1 \%$ paraphenylenediamine or toluidine blue. Ultrathin sections were cut at $70 \mathrm{~nm}$, contrasted with lead citrate, and examined either in a JEOL (Tokyo, Japan) JEM 2100 or a Carl Zeiss EM 910 transmission electron microscope. Axonal and myelin sheaths cross-sectional areas were quantified by measuring corpus callosum cross sections at $5000 \times$ magnification using the Image Pro Plus (Media Cybernetics, Bethesda, MD) morphometry software. Myelin sheath thickness was plotted over axon cross-sectional area using the statistics and data presentation software XACT! (SciLab, Hamburg, Germany).

\section{Results}

Macroscopic phenotype of Nes-Pex5 knock-out mice

The generation of Nes-Pex5 knock-out mice and demonstration of Pex5 inactivation, which was completed between embryonic day 14.5 (E14.5) and E18.5, were described previously (Baes et al., 2002; Krysko et al., 2007). Newborn Nes-Pex5 knock-out pups were indistinguishable from control littermates but they displayed a marked postnatal growth retardation (Fig. $1 A$ ). The weight gain of $~ 50 \%$ of NesPex5 knock-out mice was extremely small, and these mice died within 6 weeks of age, with a peak in the postweaning period (Fig. 1B). Three-week-old Nes-Pex5 knock-out mice developed cataract, abnormal plantar reflexes, and hindlimb flexion on lifting them by their tails. After $\sim 4$ months, motoric problems aggravated and food pellets were placed inside the cages as mice had problems to hang on the grid. Subsequently, the mice became lethargic, lost weight, and always died before or at the age of 6 months. At the time of death, adult knock-outs weighed $\sim 44-46 \%$ less compared with their littermate controls [female control (Ct) mice, $36.5 \pm 5.4 \mathrm{~g}, n=$ 14; male Ct mice, $37.4 \pm 4.5 \mathrm{~g}, n=12$; female Nes-Pex5 ${ }^{-/-}, 19.8 \pm 2.4 \mathrm{~g}, n=14$; male Nes-Pex5 $5^{-/-}, 21.0 \pm 3.3 \mathrm{~g}, n=15$ ].
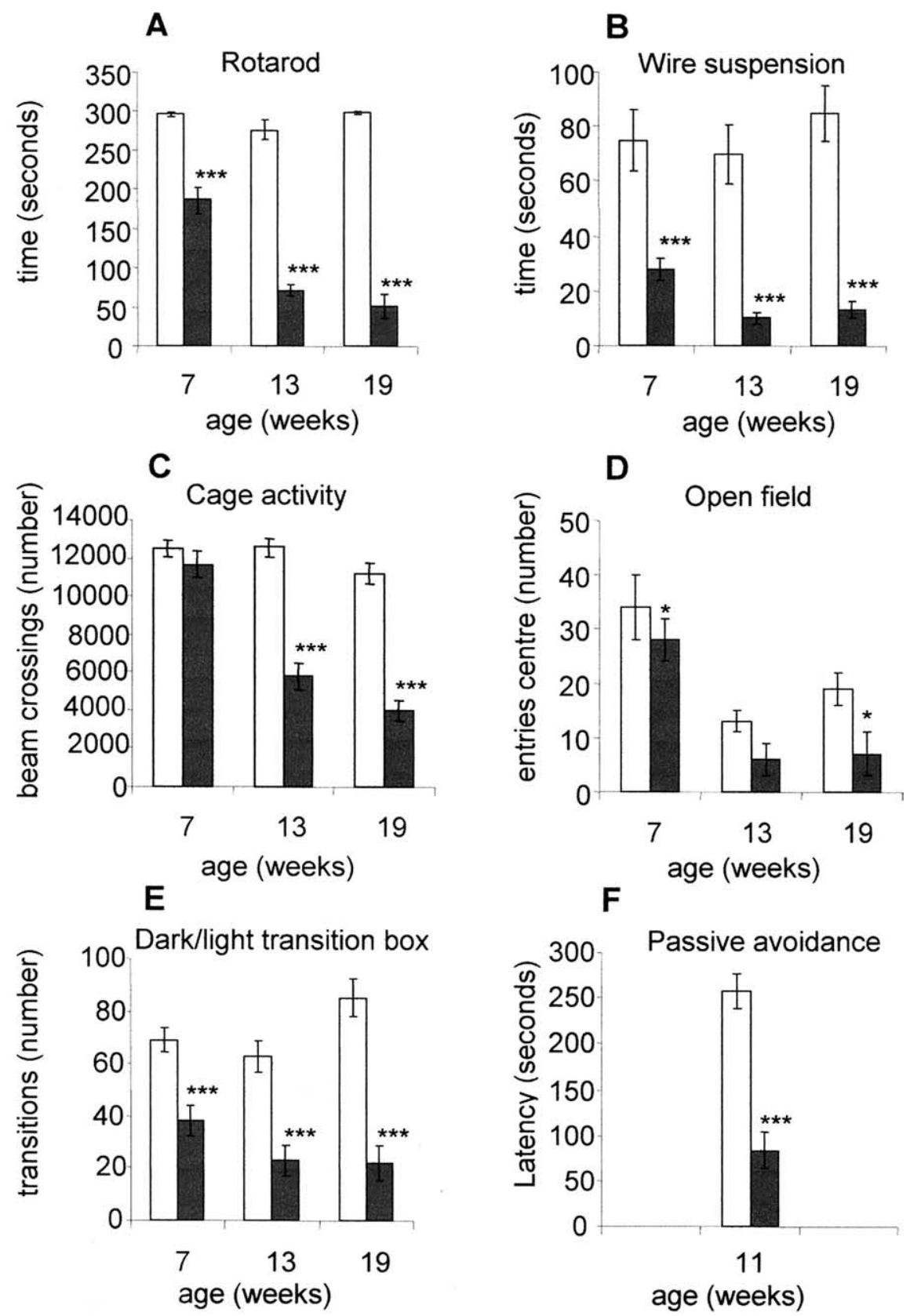

Figure 2. Behavioral analysis of Nes-Pex5 knock-out mice. A-C, Neuromotor test performance indicates progressive impairment in Nes-Pex5 knock-out mice (dark gray bars) compared with controls (white bars). Latency of falling off the rod during the fourth accelerating rotarod trial $(\boldsymbol{A})$ and of grip release during the wire suspension test $(\boldsymbol{B})$, as well as locomotor cage activity $(\boldsymbol{C})$, progressively decreased in Nes-Pex 5 knock-outs. $\boldsymbol{D}, \boldsymbol{E}$, Exploratory behavior of Nes-Pex 5 knock-out mice was also reduced. Openfield test revealed less entries in the central circle at all ages tested $(\boldsymbol{D})$, and Nes-Pex5 knock-out mice generally produced less beam crossings in the dark-light transition box $(\boldsymbol{E})$. $\boldsymbol{F}$, Finally, Nes-Pex5 knock-out mice displayed reduced latency to reenter the dark compartment in the passive avoidance learning task. The histograms depict mean values $\pm \mathrm{SEM}$. The asterisks indicate significance of differences versus control means in pairwise comparison ( post hoc Fisher's least significant difference): ${ }^{*} p<0.05$, ${ }^{* * *} p<0.001$.

\section{Behavioral phenotype of Nes-Pex5}

\section{knock-out mice}

Longitudinal behavior assessment between 7 and 19 weeks revealed progressive ataxia, dyskinesia, and decreased exploration in the Nes-Pex5 knock-out mice (Fig. 2). Asthenia and/or neuromotor defects are manifested in the knock-outs by their impaired motor performance in the rotarod, wire suspension, and cage activity tests (Fig. 2A-C). All three tests demonstrated significant effects of genotype and genotype by age interaction (two-way
ANOVA, $p<0.001$ ) on the neuromotor measures. For example, the significant effect of genotype on the rotarod measure indicates that neuromotor and coordination defects were already obvious at an age of 7 weeks $\left(F_{(1,73)}=760 ; p<0.001\right)$, but deteriorated henceforth (interaction genotype by age; $F_{(2,73)}=38 ; p<$ 0.001).

Exploration in the open-field and dark-light transition tests indicated a defect in the knock-out group that was only slightly 
Table 1. Lipid analyses in cerebrum of 5-month-old Nes-Pex5 knock-out and control mice

\begin{tabular}{lcc}
\hline & Control & Nes-Pex5 knock-out \\
\hline Plasmalogens (pmol/nmol phospholipids) & $23.4 \pm 5.5$ & $3.8 \pm 1.3^{* * *}$ \\
$C_{26: 0} / C_{22: 0}$ & $0.027 \pm 0.006$ & $0.153 \pm 0.015^{* * *}$ \\
$C_{22: 6 n-3}(\mathrm{pmol} / \mathrm{nmol}$ phospholipids) & $190 \pm 14$ & $180 \pm 4$ \\
Cholesterol ( $\mu \mathrm{mol} / \mathrm{g}$ tissue) & $16.92 \pm 0.33$ & $17.20 \pm 2.21$ \\
Cholesterylesters $(\mu \mathrm{mol} / \mathrm{g}$ tissue) & $0.05 \pm 0.01$ & $0.49 \pm 0.20^{*}$ \\
Triglycerides ( $\mu \mathrm{mol} / \mathrm{g}$ tissue) & $0.27 \pm 0.03$ & $0.46 \pm 0.05^{* *}$ \\
\hline
\end{tabular}

Values represent means \pm SEM of three or four independent samples.

${ }^{*} p<0.1,{ }^{* *} p<0.05,{ }^{* * *} p<0.005$, unpaired Student's $t$ test.

Table 2. Summary of observed pathologies in CNS of 5-month-old Nes-Pex5 knock-out mice

\begin{tabular}{|c|c|c|c|c|c|c|c|}
\hline & $\begin{array}{l}\text { Lipid accu- } \\
\text { mulation }\end{array}$ & Astrogliosis & Microgliosis & Myelin defect & Axonal damage & Cell death & $\begin{array}{l}\text { Catalase } \\
\text { upregulation }\end{array}$ \\
\hline Optic nerve & - & - & - & - & - & - & - \\
\hline Cortex & $x$ & $x x(V)$ & $x x(V)$ & $x$ & $x x(V)$ & - & $x$ \\
\hline Cc & $x$ & $x x$ & $x x x$ & $x x x$ & $x x x$ & $x$ & $x x x$ \\
\hline Fornix & $x$ & $x x$ & $x x x(V)$ & $x x x(V)$ & $x x(V)$ & - & $x x$ \\
\hline Anterior commissure & $x$ & $x x$ & $x x$ & $x(V)$ & - & - & $x x$ \\
\hline Hippocampus & $x$ & $x x$ & $x x$ & - & $x x$ & - & $x$ \\
\hline Thalamus & $x$ & $x x$ & $x x$ & - & $x x$ & - & $x x$ \\
\hline Hypothalamus & $x$ & $x x$ & $x x$ & - & $x x$ & - & $x x$ \\
\hline Sup coll & $x$ & $x x$ & $x x$ & - & $x x$ & - & $x x$ \\
\hline Inf coll & $x$ & $x x$ & $x x$ & - & $x x$ & - & $x x$ \\
\hline Midbrain & $x$ & $x x$ & $x x$ & - & $x x$ & - & $x x$ \\
\hline Pons & $x$ & $x x$ & $x x$ & - & $x x$ & - & $x x$ \\
\hline Medulla & $x$ & $x x$ & $x x$ & - & $x x$ & - & $x x$ \\
\hline \multicolumn{8}{|l|}{ Cerebellum } \\
\hline $\mathrm{ML}$ & $x x x$ & $x$ & $x$ & - & $x x$ & - & $x x$ \\
\hline GL & $x$ & $x$ & $x$ & - & $x x$ & - & $x x$ \\
\hline Whm & $x$ & $x$ & $x$ & $x x$ & $x x x$ & - & $x x x$ \\
\hline Spinal cord & $x$ & $x x$ & $x x$ & $x(V)$ & $x(V)$ & - & I \\
\hline
\end{tabular}

-, Not present; $x$, present; $x x$, more present; $x x x$, most present; $V$, variable between mice; /, not investigated. Abbreviations: Cc, corpus callosum; sup coll, superior colliculus; inf coll, inferior colliculus; ML, molecular layer; GL, granular layer; Whm, white matter.

progressive and indicative of emotional dulling at an early age (Fig. $2 D, E$ ). Total path length in the open-field test and number of corner crossings (measures of locomotor activity) were not significantly altered (data not shown in figure), whereas the number of entries in the center (Fig. 2D) and the percentage of distance in the center (data not shown) were significantly reduced $(p<0.05)$. Accordingly, Nes-Pex5 knock-out mice made significantly less exploratory transitions in the dark-light box at all ages tested (Fig. 2E).

In addition to these motoric and coordination performance tests, cognitive abilities were examined in 11-week-old mice. Despite their generally reduced activity and normal reaction to the electric shock, Nes-Pex5 knock-out mice entered the dark compartment faster than controls during the test trial of the passive avoidance task, which suggests learning/memory impairments in Nes-Pex 5 knock-out mice as well (Fig. 2 F). Together, these latter data sets demonstrate that peroxisome deficiency in brain severely affects central functions like exploratory and cognitive behaviors.

\section{Metabolic profile of Nes-Pex5 knock-out mice}

A number of metabolites that are either generated or degraded by peroxisomal pathways were analyzed in entire cerebra of 5 -month-old mice. Plasmalogens, a subclass of etherphospholipids that were reduced by $65 \%$ in brain of newborn Nes-Pex 5 knock-out mice (Krysko et al., 2007), were more profoundly depleted in 5-month-old mice (Table 1). Conversely, levels of the very long chain fatty acid (VLCFA) $\mathrm{C}_{26: 0}$ were threefold increased at birth and sixfold in adulthood (Table 1). The concentration of docosahexaenoic acid (DHA) $\left(\mathrm{C}_{22: 6 n-3}\right)$, the most abundant polyunsaturated fatty acid (PUFA) in brain that depends on one cycle of peroxisomal $\beta$-oxidation for its synthesis, was reduced in brain of newborn (Krysko et al., 2007) but not in adult mice (Table 1). Although astrocytes are capable of synthesizing DHA from n-3 PUFA precursors, these data confirm previous suggestions that most of the DHA in brain is acquired from the diet or from synthesis in the liver (Williard et al., 2001). Finally, there was no decrease of cholesterol levels in Nes-Pex5 knock-out mice, contradicting previously proposed roles for peroxisomes in isoprenoid biosynthesis (Biardi and Krisans, 1997) (Table 1). A more generalized lipid profile analysis revealed that the concentration of phospholipids was unaltered but that triglycerides and cholesterylesters were 2 - and 10-fold increased in cerebra of Nes-Pex5 knockout mice, respectively (Table 1).

\section{Multiple pathologies in the CNS but no anomalies in the peripheral neuromuscular system}

Because the nestin promoter drives Cre expression in brain and spinal cord, we first evaluated whether the motoric impairments could be attributable to neuromuscular lesions (e.g., by affecting spinal motoneurons). Histological analysis of highresolution semithin sections of peripheral nerves, light microscopy of muscle (data not shown), and measurement of compound motor action potentials did not reveal differences between control (17.73 \pm $1.74 \mathrm{mV}$ ) and Nes-Pex5 knock-out mice at the age of 5 months $(19.45 \pm 3.11 \mathrm{mV})(n=3)$. Latencies of compound motor action potentials were $0.82 \pm 0.04 \mathrm{~ms}$ in controls versus $0.85 \pm 0.02 \mathrm{~ms}$ in Nes-Pex 5 knock-out mice.

In marked contrast, as described in detail below, the CNS of Nes-Pex5 knock-out mice develops a complex phenotype characterized by region-specific lipid storage, gliosis, axon degeneration, and changes in myelin sheath composition (summarized in Table 2).

\section{Lipids accumulate in brain and spinal cord}

Oil Red O stainings were done to define the site of neutral lipid accumulations (Table 1) in 5-month-old Nes-Pex5 knock-out mice. Lipid inclusions were most prominent in the ependymal lining of cerebral ventricles (Fig. $3 A, B, G$ ) and the central canal of the spinal cord (Fig. 3C,D). No lipid accumulations were observed in the choroid plexus. In addition to ependymal cells, Oil Red O-positive lipid droplets extensively accumulated in the molecular layer of the cerebellar cortex (Fig. $3 E, F$ ). More specifically, they were present in Bergmann glia fibers, neurite processes, and glial endfeet at the pial basement membrane and strikingly in cerebellar meningeal cells, whereas meningeal cells elsewhere in the CNS were unaffected (Fig. $3 H$ ). To a much lesser extent, lipid droplets were spread over all gray matter areas such as the granular layer of the cerebellum, the cerebral cortex, hippocampus, the hypothalamus and thalamus, and the superior and inferior colliculi (Table 2). In addition, lipid droplets were found in the corpus callosum and white matter of cerebellum. 

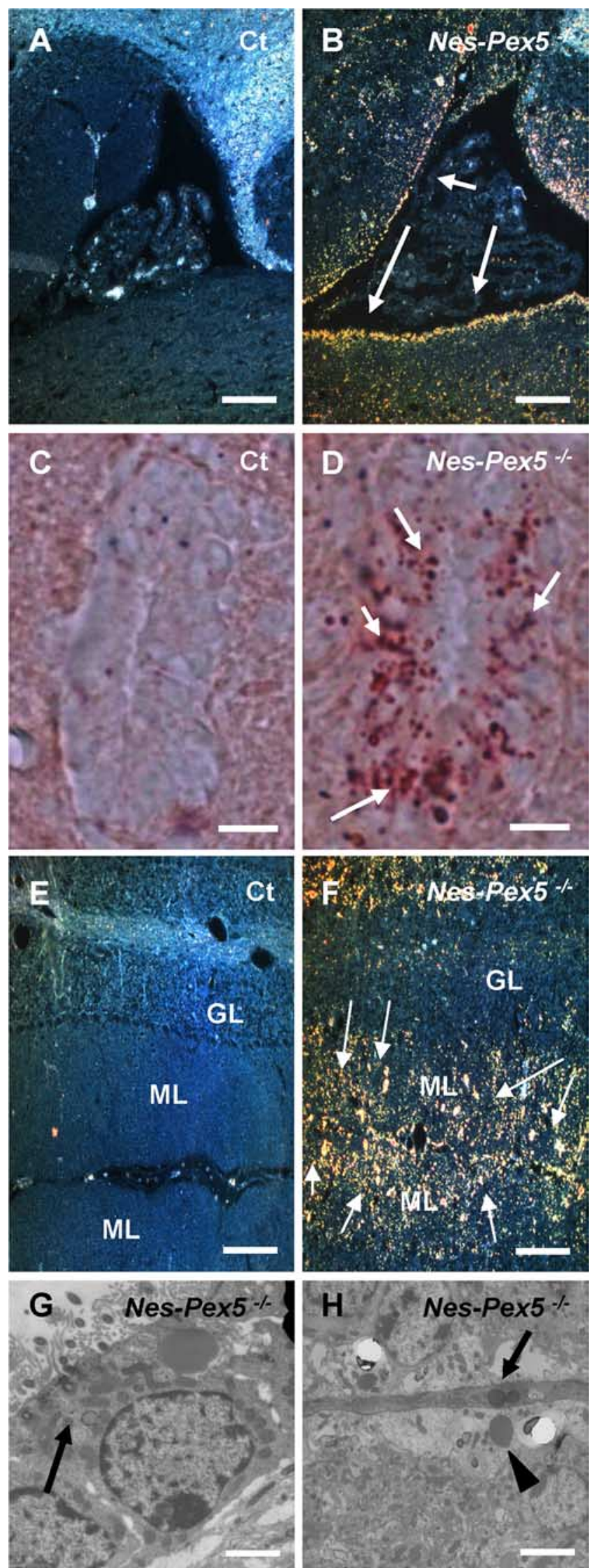

Figure 3. Accumulation of lipids in the CNS of Nes-Pex5 knock-out mice. Oil Red 0 staining reveals neutral lipid accumulations in ependymal cells surrounding the fourth ventricle $(\boldsymbol{B})$ and the central canal of the spinal cord $(\boldsymbol{D})$ but not in the choroid plexus epithelium in Nes-Pex5 knock-out mice. In control mice, no lipid droplets were detected $(\boldsymbol{A}, \boldsymbol{C})$. Lipid accumulations
Peroxisome deficiency causes severe gliosis in brain and spinal cord

Both as a readout for any kind of pathological changes in the CNS as well as to investigate whether the elimination of functional peroxisomes affects the glial compartment, immunohistochemical detection of astrocyte and microglial markers was performed between the ages of 3 weeks and 5 months.

Increased expression of GFAP, the common marker of astroglial activation, was clearly visible from 3 weeks on in spinal cord (supplemental Fig. $1 A, B$, available at www.jneurosci.org as supplemental material) and from 6 weeks on in gray and white matter of all brain regions of Nes-Pex5 knock-out mice (Fig. $4 B$, shown for 3-month-old mouse). Marked regional differences in severity of astrogliosis were observed being most extensive in cerebral cortex and corpus callosum (Fig. $4 B, F$ ). In Table 2, the severity and distribution of gliosis in 5-month-old mice is shown.

Astrocytes in mutant mice had the morphology of reactive astrocytes with large swollen cell bodies and complex ramified cellular processes (Fig. $4 F^{\prime}$ ). In contrast, astroglial cells identified in control mice had small cell bodies and less cellular processes (Fig. $4 E^{\prime}$ ). Western blotting of brain homogenates confirmed the upregulation of the astrocytic marker in Nes-Pex5 knock-out mice (data not shown).

Immunoreactivity of the macrophage/microglia surface molecule F4/80 was massively increased at an age of 3 weeks in spinal cord (supplemental Fig. 1C,D, available at www.jneurosci.org as supplemental material) and 6 weeks in brain of Nes-Pex 5 knockout mice, pointing to the activation of microglial cells. This microgliosis was observed in all brain regions but was most pronounced in white matter (Fig. $4 D, H$, Table 2). Microglial cells in mutant mice exhibited thickened processes and increased cell body size, but ameboid microglia were not observed (Fig. $4 H^{\prime}$ ). In contrast, microglia identified in control mice had small cell bodies and finer cytoplasmatic ramifications (Fig. $4 G^{\prime}$ ). Both the expression of F4/80 and GFAP increased during the lifetime of Nes-Pex5 knock-out mice.

To determine whether astrogliosis and microgliosis was associated with lymphocyte influx, we tested for infiltrating $\mathrm{T}$ cells with anti-CD3 antibody. No T cells were found at any age tested. In addition, an immunohistochemical staining with CD45, a pan-leukocyte marker gave a very similar staining pattern to F4/ 80 , suggesting that the vast majority of CD45 staining was attributable to microglia/macrophages (data not shown).

\section{Peroxisomal catalase is upregulated}

Catalase, the enzyme that inactivates toxic peroxides produced by peroxisomal oxidases and other cellular sources, is one of the exceptional peroxisomal enzymes that are stable and active when mislocalized to the cytosol. Immunohistochemical stainings revealed that catalase was extensively upregulated in white matter areas (Fig. 5A,B) of Nes-Pex5 knock-out mice and to a variable extent in Bergmann glial cells of the cerebellum (Fig. 5C,D) already from an age of 3 weeks. Western blot analysis on cerebral homogenates confirmed the upregulation starting from an age of 3 weeks in Nes-Pex 5 knock-out mice. The increase was not attrib-

were also abundant in the molecular layer of the cerebellum of Nes-Pex5 knock-out mice $(\boldsymbol{F})$ but were absent from control mice $(\boldsymbol{E})$. The arrows point to the lipid droplets that appear yellow/ pink in dark field $(\boldsymbol{B}, \boldsymbol{F})$ and red in light field $(\boldsymbol{D})$ optics. $\boldsymbol{G}, \boldsymbol{H}$, Electron micrograph of lipid droplets in an ependymal cell $(\boldsymbol{G})$ and in Bergmann glia endfeet (arrowhead) and cerebellar meningeal cells (arrow) $(\boldsymbol{H})$. Scale bars: $\boldsymbol{A}, \boldsymbol{B}, \boldsymbol{E}, \boldsymbol{F}, 100 \mu \mathrm{m} ; \boldsymbol{C}, \boldsymbol{D}, 50 \mu \mathrm{m} ; \boldsymbol{G}, 2 \mu \mathrm{m} ; \boldsymbol{H}, 5 \mu \mathrm{m}$. GL, Granular layer; $\mathrm{ML}$, molecular layer. 

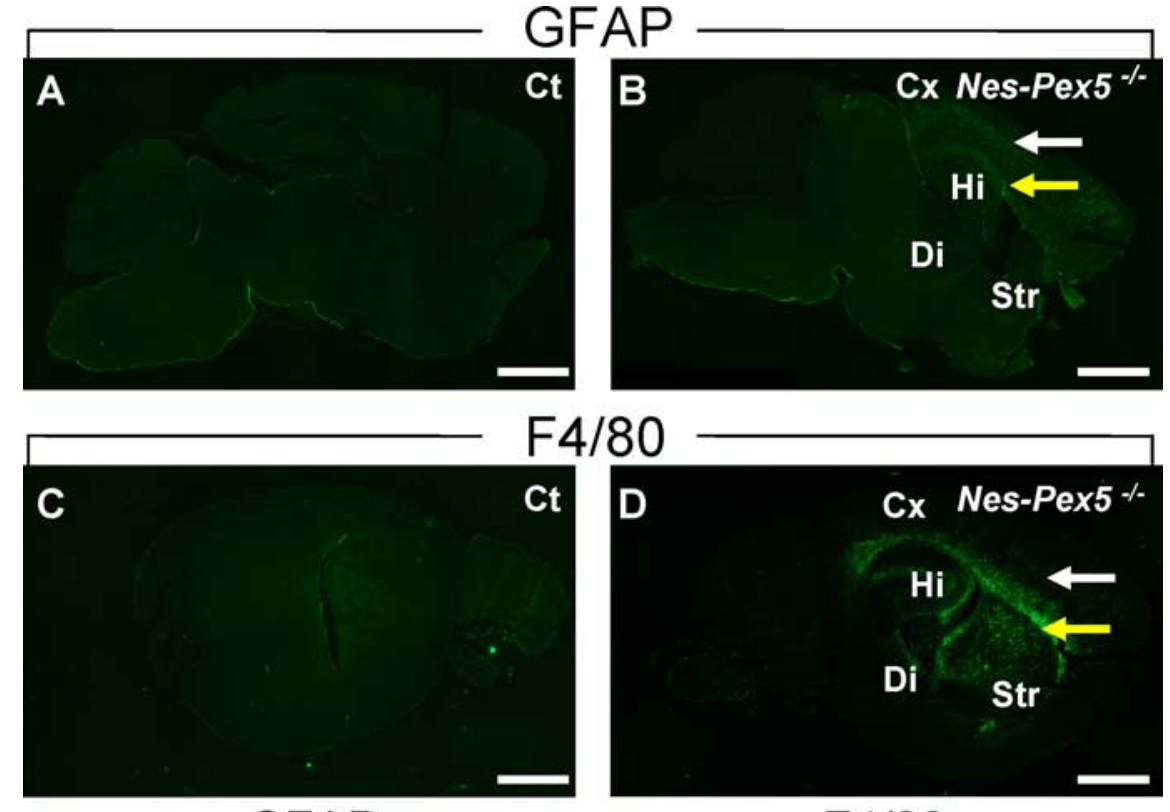

$4 / 80$
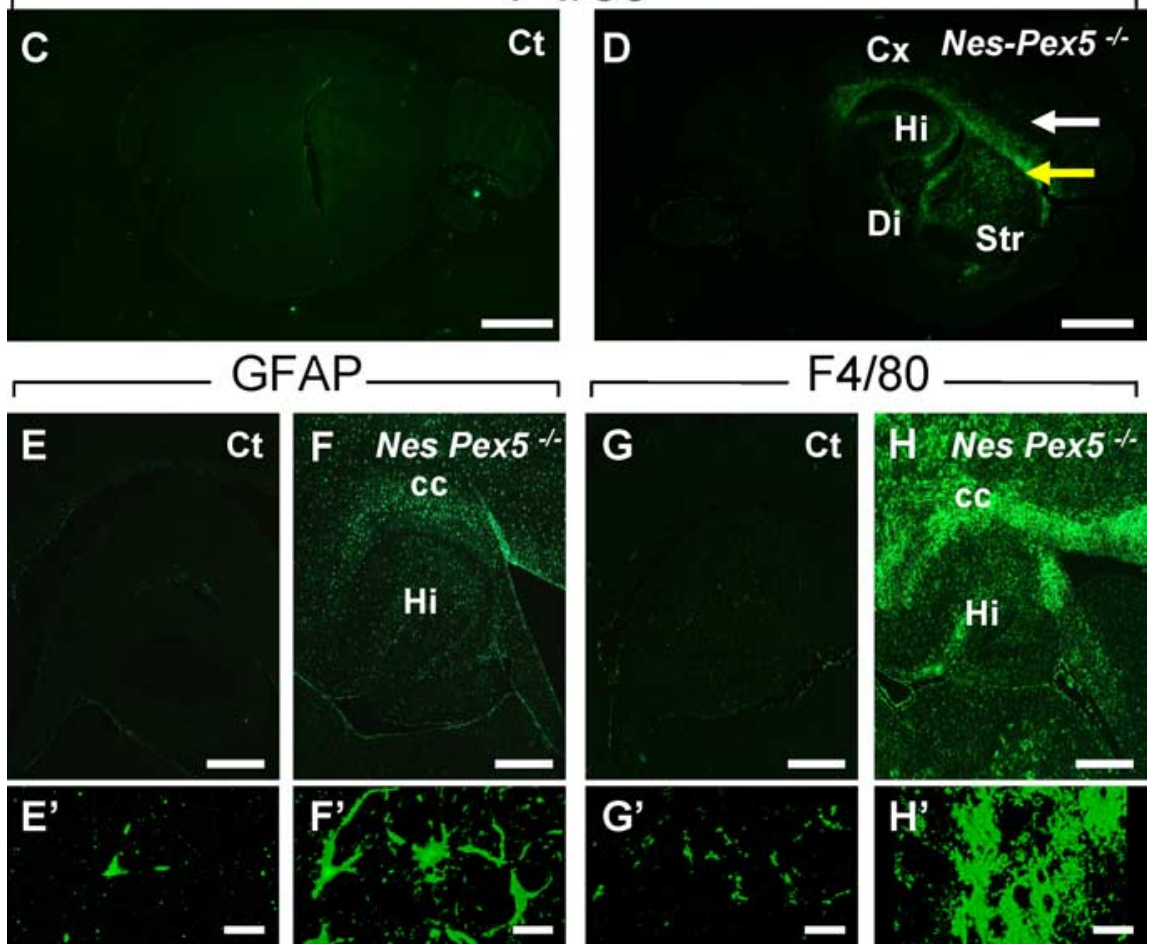

Figure 4. Glial reactions in the CNS of Nes-Pex5 knock-out mice. Astroglial activation as evidenced by enhanced GFAP staining in a 3-month-old Nes-Pex5 knock-out mouse $(\boldsymbol{B})$ compared with a littermate control mouse $(\boldsymbol{A})$. The strongest reaction is found in the cerebral cortex ( $(\mathrm{X})$ [approximately laminas (3/4)] ( $\boldsymbol{B}$, white arrow) and to a lesser extent in the corpus callosum (Cc) (B, yellow arrow; shown in more detail in $\boldsymbol{F}$ ). Hippocampus (Hi), corpus striatum (Str), and diencephalon (Di) were less affected at this stage. Astrocytes in mutant mice had the morphology of reactive astrocytes with large swollen cell bodies and complex ramified cellular processes $\left(\boldsymbol{F}^{\prime}\right)$, whereas those in control mice showed smaller cell bodies and less processes $\left(\boldsymbol{E}^{\prime}\right)$. Staining with antibodies to the surface marker $\mathrm{F} 4 / 80$ of microglial cells showed massive microgliosis in cc (yellow arrow) and less pronounced reactions in the $C x$ (white arrow) of 3-month-old Nes-Pex5 knock-out mice $(\boldsymbol{D}, \boldsymbol{H})$ in comparison with control mice $(\boldsymbol{C}, \boldsymbol{G})$. Notably, a marked microgliosis also was seen in the fimbria and hippocampal fissure of $\mathrm{Hi}$, Str, and less $\mathrm{so}$ in Di. Microglial cells in mutant mice were activated with thickened processes and increased size of cell body $\left(\boldsymbol{H}^{\prime}\right)$ in contrast to microglia in control mice $\left(\boldsymbol{G}^{\prime}\right)$. DG, Dentate gyrus. Scale bars: $\boldsymbol{A}-\boldsymbol{D}, 4 \mathrm{~mm} ; \boldsymbol{E}-\boldsymbol{H}, 500 \mu \mathrm{m} ; \boldsymbol{E}^{\prime}-\boldsymbol{H}^{\prime}, 0.10 \mu \mathrm{m}$. Exposure times of knock-out and control sections were always the same with the exception of $\boldsymbol{E}^{\prime}-\boldsymbol{H}^{\prime}$, in which longer exposure was used for the controls to allow visualization of the cell shape.

utable to transcriptional induction because there were no differences in catalase mRNA levels as determined by quantitative PCR (data not shown). Double stainings with GFAP and CC1, respectively, in adult mouse brain revealed that catalase was primarily present in activated astrocytes (Fig. $5 E$, in corpus callosum; $F$, in white matter of cerebellum) and in oligodendrocytes (Fig. 5G, in corpus callosum; $H$, in white matter of cerebellum) in Nes-Pex5 knock-out mice but not in microglia (data not shown).

\section{Peroxisome deficiency is associated with} myelin abnormalities

Already in young 3-week-old Nes-Pex5 knock-out mice, visualization of myelin with LFB showed a clear reduction of stainabil- ity, which was most obvious in the corpus callosum and less pronounced in cerebellum (Fig. 6A-D), but appeared to spare other myelinated fiber tracts. The difference with control littermates progressively increased during later stages (Fig. $7 A, B$, Table 2). The decrease of LFB staining was paralleled by an almost complete loss of immunoreactivity of the myelin proteins $\operatorname{MBP}$ (Figs. $6 E-H, 7 C, D, I, J$ ) and PLP (data not shown) at all stages tested. For PLP, some residual staining was observed in cerebellum. Because MBP and PLP are only distributed in compact myelin, we also tested CNP, present in abaxonal, periaxonal and paranodal loops of uncompacted myelin (Gielen et al., 2006). Loss of CNP immunoreactivity was demonstrated at all ages tested throughout the CNS (Fig. $7 E, F)$. When the stainings for MBP and CNP were repeated on acetone-fixed frozen sections instead of formalin-fixed paraffin sections, MBP remained undetectable (Fig. 7I,J) but CNP immunoreactivity was now indistinguishable between control and knock-out mice (Fig. 7G,H). Finally, immunostaining of MAG, which is confined to the periaxonal space of the myelin sheath (Quarles, 2007) and which could only be detected on frozen sections, was normal in knock-out mice (Fig. $7 K, L$ ).

To further investigate the expression of myelin proteins, Western blot analyses were performed on microdissected corpus callosum (Fig. 7M). The immunoreactivity of MBP was approximately halved, whereas the expression of CNP (Fig. 7M) and MAG (data not shown) was practically unaltered in Nes-Pex 5 knock-outs.

Together, these data indicate that myelin proteins are still present, but that in particular the immunohistochemical detection of proteins present in compact myelin is severely impaired. Although the loss of MBP immunoreactivity in the sections might be attributable to a sensitivity problem, the differential detection of CNP, depending on the procedure used, might indicate that the proteins are embedded in an altered lipid environment within the myelin sheath.

To exclude that reduced myelin staining was attributable to reduced numbers of mature oligodendrocytes, these cells were detected with the oligodendrocyte-specific antibody CC-1 in 3 -week-old mice, but no differences between knock-outs and controls were observed $(367.69 \pm 12.35$ in control vs $353.00 \pm$ 15.55 in knock-out oligodendrocytes per square millimeter of corpus callosum).

When myelin was isolated from total brain of 6-week-old mice, clearly lower yields were obtained from Nes-Pex5 knockout compared with control mice. The lipid content/composition was further analyzed by thin-layer and gas chromatography. Basically, the same changes were seen as in total cerebral extracts (i.e., alkenyl-phospholipids were completely absent and replaced 

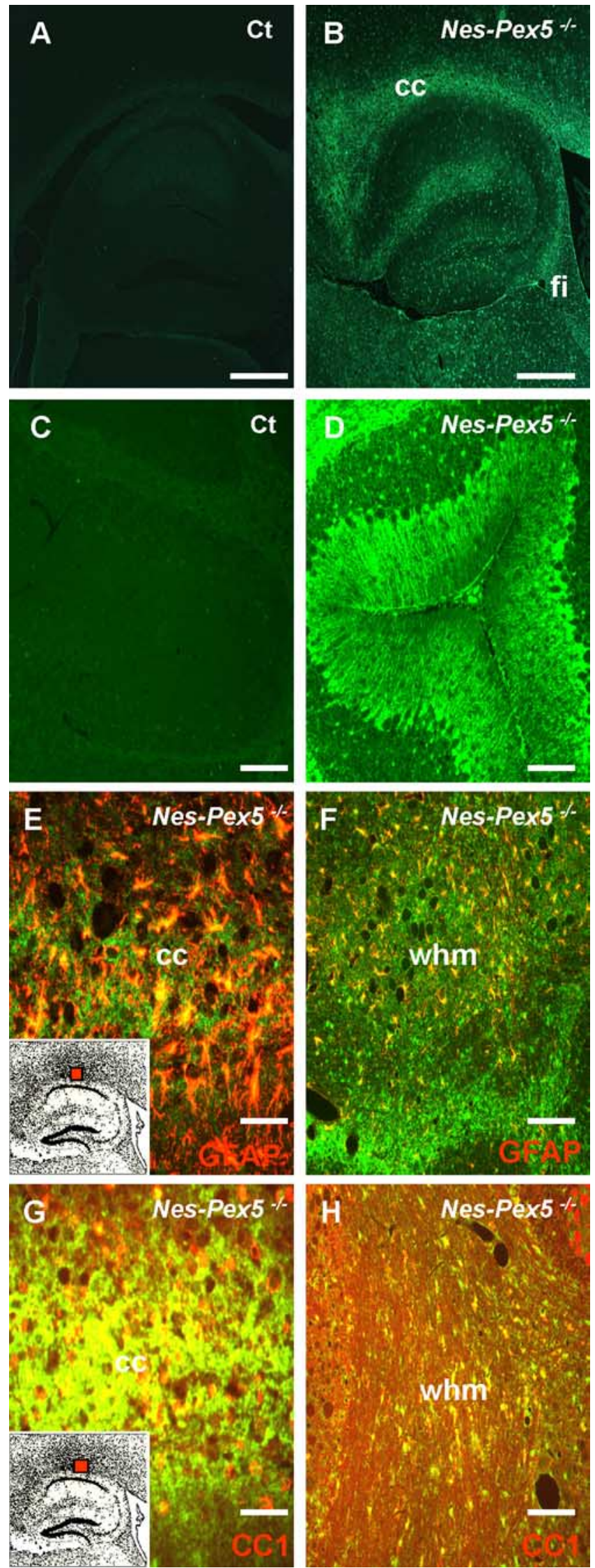

Figure 5. Catalase upregulation in brain of Nes-Pex5 knock-out mice. A-D, Upregulation of the peroxisomal enzyme catalase was already present at the age of 3 weeks predominantly in white matter areas such as corpus callosum (cc) (B) and cerebellum (D) in Nes-Pex5 knock-out mice in comparison with control mice $(\boldsymbol{A}, \boldsymbol{C}) . \boldsymbol{E}-\boldsymbol{H}$, Colocalization studies in 5-month-old by acyl-phospholipids), and the ratio of $\mathrm{C}_{26: 0} / \mathrm{C}_{22: 0}$ was increased from $<0.05$ to 0.15 . The stoichiometry of cholesterol versus phospholipids levels was not altered (data not shown).

\section{Peroxisome deficiency causes axonal damage}

To examine the status of axons in Nes-Pex5 knock-out mice, an immunohistochemical detection of unphosphorylated neurofilaments, which are characteristic for axonal damage, was performed. Whereas neurofilaments in control mice were heavily phosphorylated and not stained with SMI32 antibody (Fig. $8 A, C)$, axons staining for nonphosphorylated neurofilaments were observed in coronal sections of corpus callosum of 3-month-old (data not shown) and 5-month-old Nes-Pex5 knock-out mice (Fig. $8 B, D$ ) but not at an age of 3 or 6 weeks. This was also confirmed by using immunohistochemistry for APP, which is produced in neurons and accumulates within local swellings along the trajectory of damaged or retracting axons because of the disturbance of axonal transport. Damaged axons were not only observed in white matter (Fig. $8 E, F$ ) but also in the gray matter such as the dentate gyrus and CA1 area of the hippocampus (Fig. $8 G, H$, Table 2 ).

\section{Ultrastructural anomalies of myelinated axons in Nes-Pex5 knock-out mice}

A further investigation of corpus callosum, fornix, and optic nerve in resin-embedded Nes-Pex5 knock-out tissues revealed a major reduction of myelin stainability by toluidine blue and p-phenylenediamine in corpus callosum of 5-month-old mice (Fig. 9A,B), which was already present in 3-week-old mice (data not shown). Strikingly, the extent of the staining defect appeared to be strongly regionalized. On a corpus callosum cross section, large patches of several hundred square micrometers appeared without any stainable myelin surrounded by weakly or near-tonormal staining myelinated axons. This was less pronounced in fornix, whereas the optic nerve appeared ultrastructurally normal even at the latest stages investigated and also remained free of unspecific signs of pathology like astrogliosis and microgliosis.

At the ultrastructural level, next to numerous normally appearing axons with apparently intact myelin sheaths, axons with thinned myelin sheaths were observed (Fig. 9D,E). This was confirmed by $g$-ratio measurements of corpus callosum axons, represented as the myelin sheath cross-sectional area plotted as a function of the respective axon cross-sectional areas of WT, 5and 6-month-old knock-out mice (supplemental Fig. 4, available at www.jneurosci.org as supplemental material).

More strikingly, in a subset of axons a clear detachment of the inner myelin sheath wrappings from the axonal surface was seen, apparently resulting in a fluid-filled or extracellular matrix-filled space between the inner myelin lamella and axon membrane (Fig. $9 D)$. These features of axonal detachment and collapse could be even better appreciated on longitudinal sections through myelinated axons in corpus callosum (Fig. 9 J, K). Importantly, damaged axons characterized by caliber irregularities, clumped microtubules, and/or agglomerations of mitochondria, vesicles, and whorls of membrane material were often encountered without

Nes-Pex5 knock-out mice revealed that catalase was predominantly present in activated astrocytes [in corpus callosum $(\boldsymbol{E})$ and in white matter of cerebellum (whm) $(\boldsymbol{F})$ ] and in oligodendrocytes [in $c(\boldsymbol{G})$ and in whm $(\boldsymbol{H})$ ]. An overlay of catalase stained in green and either the astrocyte marker, GFAP, or oligodendrocyte marker, $\mathrm{CC} 1$, stained in red is shown. The red squares in the insets in $\boldsymbol{E}$ and $\boldsymbol{G}$ indicate in which region of the brain pictures are taken. Scale bars: $\boldsymbol{A}, \boldsymbol{B}, 500$ $\mu \mathrm{m} ; \mathbf{C}-\boldsymbol{H}, 100 \mu \mathrm{m}$. 
LFB

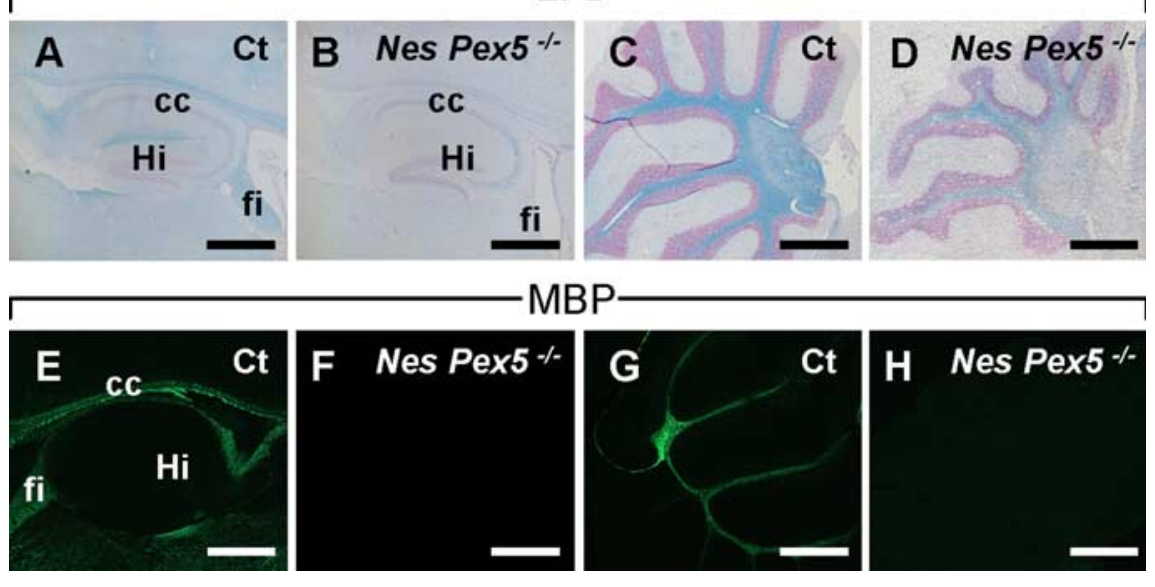

Figure 6. Myelin abnormalities in the CNS of 3-week-old Nes-Pex5 knock-out mice. $\boldsymbol{A}-\boldsymbol{D}$, LFB staining to detect myelin is severely reduced in corpus callosum (cc), fimbriae (Fi) $(\boldsymbol{B})$, and cerebellum $(\boldsymbol{D})$ of 3-week-old Nes-Pex5 knock-out mice in comparison with control mice $(\boldsymbol{A}, \boldsymbol{C}$. $\boldsymbol{E}-\boldsymbol{H}$, Using the same exposure times, the fluorescent signal after immunostaining of brain sections with MBP antibodies was dramatically reduced in corpus callosum $(\boldsymbol{F})$ and cerebellum $(\boldsymbol{H})$ of 3-week-old Nes-Pex5 knock-out mice compared with control mice $(\boldsymbol{E}, \boldsymbol{G})$. Hi, Hippocampus. Scale bars, $500 \mu \mathrm{m}$.

clear defects of the immediately surrounding myelin sheaths (Fig. $9 J, K)$.

This was also illustrated in a mouse surviving until the age of 6 months (Fig. 9F) in which prominent myelin destruction and axonal collapses occurred but which did not always colocalize. No obvious morphological alterations were noticed in oligodendrocyte cell bodies (Fig. 9H,I). Together, the data indicate that axon damage either precedes myelin sheath degeneration or that both pathological events may occur independently.

Another striking feature that could be observed on longitudinal sections was that axon damage does not extend over the entire length of the axon but can be limited to (a part of) an internodium (data not shown). Additionally, these sections revealed that nodal regions were unusually broad in a fraction of Ranvier nodes (Fig. 9N). At the Ranvier nodes, we also encountered enlarged lamellas of decompacted myelin, which then continued in still normally wrapped myelin in the internodal region (Fig. 9M).

These axonal abnormalities were first observed in 3-week-old mice and aggravated during the lifetime of the knock-out mice.

\section{Limited cell death in Nes-Pex 5 knock-out brain}

To examine whether astrogliosis and microgliosis and axonal degeneration are accompanied by apoptotic cell death, cleaved caspase-3 stainings were performed. Few immunopositive cells were observed in 5-month-old Nes-Pex5 knock-out brain, which were predominantly present in the corpus callosum (supplemental Fig. 2, available at www.jneurosci.org as supplemental material) and which contained oligodendroglial or astroglial markers based on double immunohistochemical stainings (data not shown). There were no signs of cerebellar atrophy, nor of Purkinje or granule cell loss, which are lesions described in rhizomelic chondrodysplasia punctata (RCDP) patients. This was confirmed by normal Purkinje cell densities and regular arborization, visualized by hematoxylin and eosin staining on cerebellum of 5-month-old Nes-Pex5 knock-out mice (supplemental Fig. 2, available at www.jneurosci.org as supplemental material). Furthermore, calbindin mRNA levels, a measure for the number of Purkinje cells (Ge et al., 2004), were unaltered in Nes-Pex5 knockout mice versus control mice $(0.76 \pm 0.18$ vs $0.67 \pm 0.08$ copies calbindin/HPRT).

\section{Discussion}

The importance of peroxisomes for establishing normal cortical and cerebellar lamination during brain development has been amply documented by the phenotypes of peroxisome diseases in humans and knock-out models in mice. A surprising recent finding was that absence of peroxisomal metabolism from liver has a more severe and permanent impact on the formation of cortex and cerebellum of the mouse compared with absence from the CNS (Krysko et al., 2007). Nes-Pex5 knock-out mice, in which functional peroxisomes were ablated from all neural cells before birth, exhibit a delay of cortical neuronal migration and cerebellar formation, but they do not display apparent architectural abnormalities at weaning. Here, we demonstrate that peroxisomes within the CNS are crucial for normal motoric and cognitive behavior and survival and that these organelles play an essential role in the formation and maintenance of myelinated axons.

\section{Myelin anomalies}

Nes-Pex 5 knock-out mice developed several lesions in white and gray matter areas. By far the most prominent defects were those of myelinated axons in the white matter of the corpus callosum and cerebellum.

At the EM level, most axons were still surrounded by myelin sheaths in these brain areas at the time of death, but abnormalities were observed, including thinner sheaths and irregularities at the Ranvier nodes.

These moderate structural changes are in contrast with the minimal signals obtained with lipid stains that are routinely used to visualize myelin. Similarly, proteins located in compact myelin (MBP and PLP) were hardly or not detectable by immunohistochemical stainings at all ages, although they could be visualized by Western blot analysis. Even more striking, the noncompact myelin protein CNP could be detected by Western blots and on frozen sections, but could not be visualized on formalin-fixed paraffin sections. It seems, therefore, that the myelin sheaths that are formed in the absence of peroxisomal metabolism are thoroughly disorganized with regard to their lipid/protein composition hampering their reactivity with dyes or antibodies.

It is unclear, at this point, which metabolic factors contribute to the myelin abnormalities. Interestingly, delayed myelin maturation and dysmyelination were not only reported in patients of the Zellweger spectrum but also in patients with selective peroxisomal enzyme disorders [i.e., in RCDP patients carrying defects in the etherlipid synthesis pathway and in multifunctional protein-2 (MFP-2)-deficient patients with peroxisomal $\beta$-oxidation impairment]. It was shown that the extent of plasmalogen loss, which encompasses $20-30 \%$ of myelin phospholipids, correlates with myelin deficiency in RCDP patients (BamsMengerink et al., 2006). In Nes-Pex5 knock-out mice, plasmalogens were completely absent from myelin but were replaced by esterphospholipids. Because the precise role of ether, as opposed to esterphospholipids, is an unresolved issue, the consequence of this switch for the formation and maintenance of myelin remains hypothetical. Ether-bonded lipids might have a double role in lipid raft microdomains because, on the one hand, plasmenylethanolamines are enriched in these domains (Pike et 
al., 2002; Rodemer et al., 2003), and, in addition, many GPI anchored proteins contain a 1-alkyl-2-acyl-glycerol moiety in their lipid anchor (Gorgas et al., 2006). This is relevant for the organization of myelin because several myelin proteins like PLP, CNP, and oligodendrocyte-myelin glycoprotein are enriched in lipid rafts (DeBruin and Harauz, 2007).

The potential compounds that impair myelin formation in patients with a defect in the peroxisomal $\beta$-oxidation enzyme MFP-2 are less clear (Ferdinandusse et al., 2006). Complicating this matter is the observation that the knock-out mouse model deviates from the patients, because no developmental myelin defects were seen in MFP-2 knock-out mice (Huyghe et al., 2006b). Although VLCFA were often claimed to contribute to membrane abnormalities, there is no definitive proof of their pathogenic role.

An open question is whether the malformed myelin is less stable and whether it affects the nodal/paranodal distribution of ion channels. Myelin abnormalities may indeed cause an altered distribution of the Kv1 type $\mathrm{K}^{+}$channels, which was shown to affect axonal conductance in dysmyelinated spinal cord (Sinha et al., 2005). The irregularities in myelin structure that were observed in all 5-month-old Nes-Pex5 knock-out mice and a single observation of severe myelin destruction in a mouse surviving for 6 months point to impaired maintenance of myelin in the absence of functional peroxisomes.

\section{Axonal anomalies}

The most common lesion in axons of NesPex $5^{-1-}$ mice was the detachment of the axon from the inner myelin lamella which further proceeded in axonal collapse and the accumulation of vesicular material and mitochondrial remnants in the periaxonal space. Although this axonal damage seems to develop simultaneously with myelin lesions, being already present in juvenile mice and aggravating during their lifetime, longitudinal sections through axons clearly demonstrated that they do not always colocalize on the same axonal segment. Indeed, areas of axonal collapse or total absence of axonal structures were surrounded by myelin sheaths of rather normal morphology. This finding is especially intriguing in the context of another study using mice with oligodendrocyte-selective Pex5 inactivation (CNP-Pex5 knock-out) (Kassmann et al., 2007). In these mice, myelinated axons were morphologically normal until the age of 2 months, but thereafter the animals developed widespread axonal degeneration and progressive subcortical demyelination from the age of 4 months accompanied with ataxia, tremor, and death before the age of 12 months. It is thus striking that we observe an earlier onset of

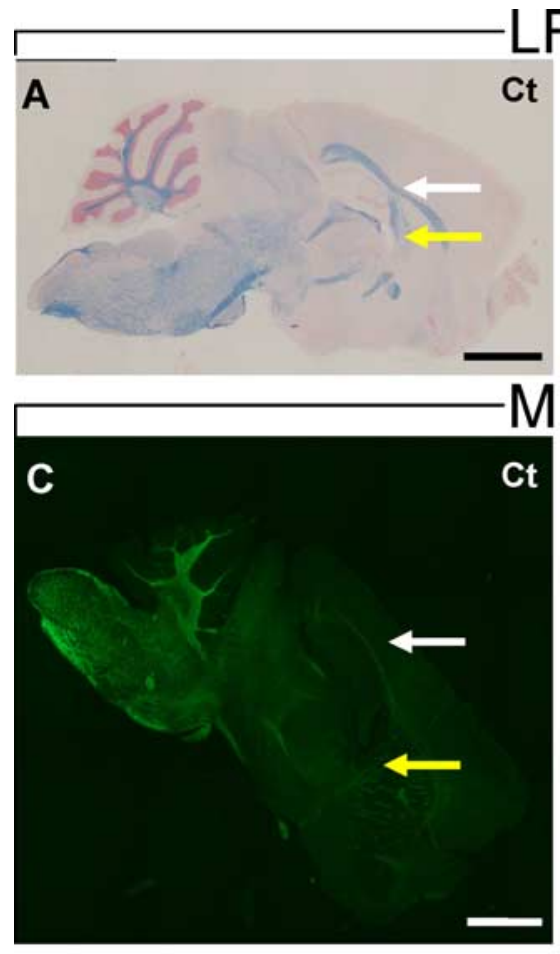

LFB
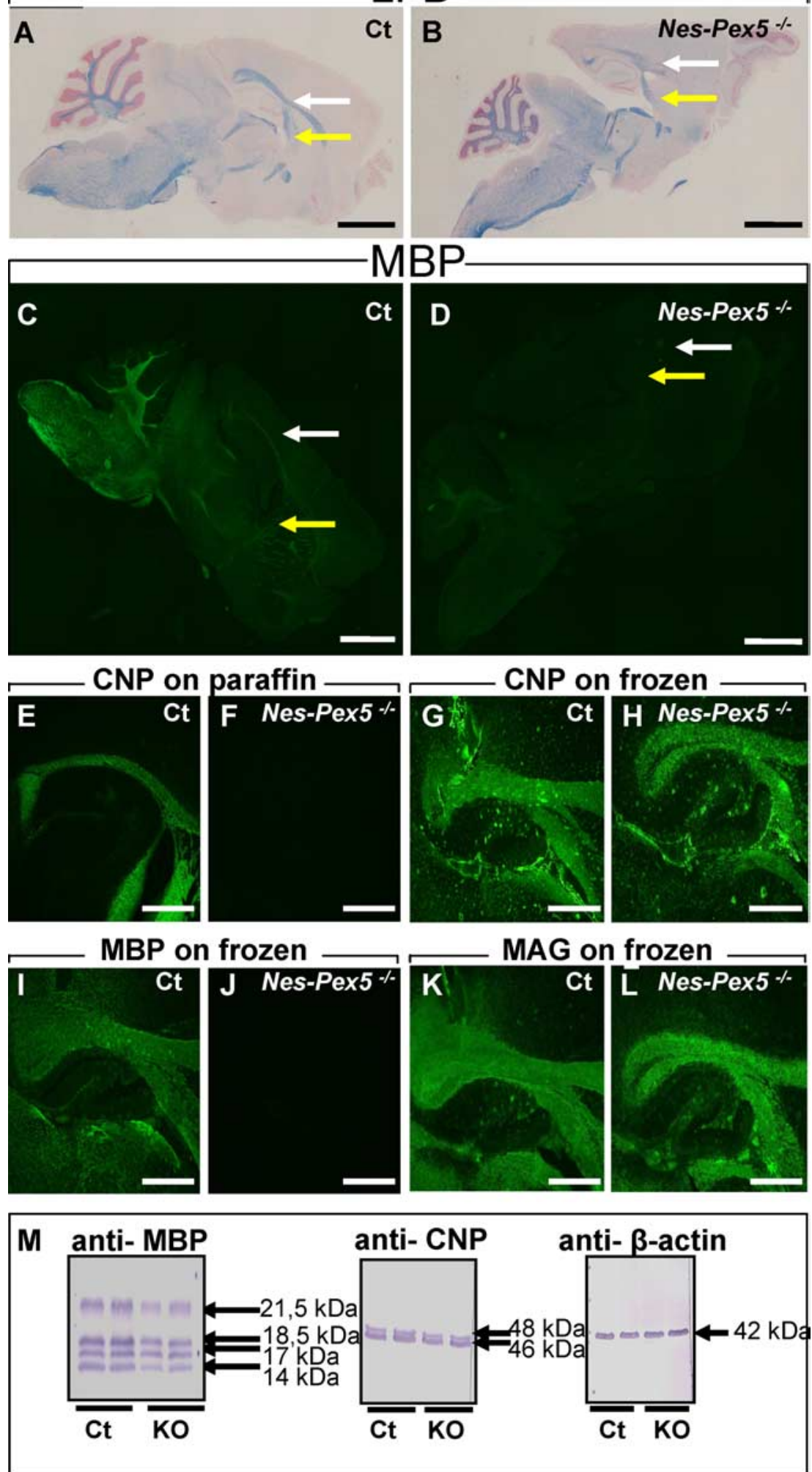

Figure 7. Myelin abnormalities in the CNS of 3-month-old old Nes-Pex5 knock-out mice. Luxol fastbluestaining $(A, B)$ produced much weaker signals in corpus callosum (white arrow) of knock-out mice, whereas other myelinated tracts like fornix (yellow arrow) were relatively preserved. In contrast, MBP immunostaining was virtually lost throughout the CNS on paraffin sections (D) and frozen sections $(J)$. Staining for $(N P$, a protein present in noncompact myelin, varied according to the fixation protocol. CNP was barely detectable in formalin-fixed paraffin sections of Nes-Pex5 knock-out mice $(\boldsymbol{F})$ but was not distinguishable from controls in acetone-fixed frozen sections $(\boldsymbol{G}, \boldsymbol{H})$. Immunoreactivity for MAG, a protein that exclusively occurs in the periaxonal loop, was not different between control $(\boldsymbol{K})$ and knock-out mice $(\boldsymbol{L})$ on frozen sections. Scale bars: $\boldsymbol{A}-\boldsymbol{D}, 4 \mathrm{~mm} ; \boldsymbol{E}-\boldsymbol{L}, 500 \mu \mathrm{m}$. $\boldsymbol{M}$, Myelin proteins were detected in microdissected corpus callosum of 5-month-old knock-out mice by Western blot analysis. Immunoreactivity of all isoforms of MBP was markedly reduced in knock-out brain, whereas CNP immunoreactivity was only slightly reduced. Equal intensity of immunoreactivity of $\beta$-actin confirmed equal loading of the samples. 


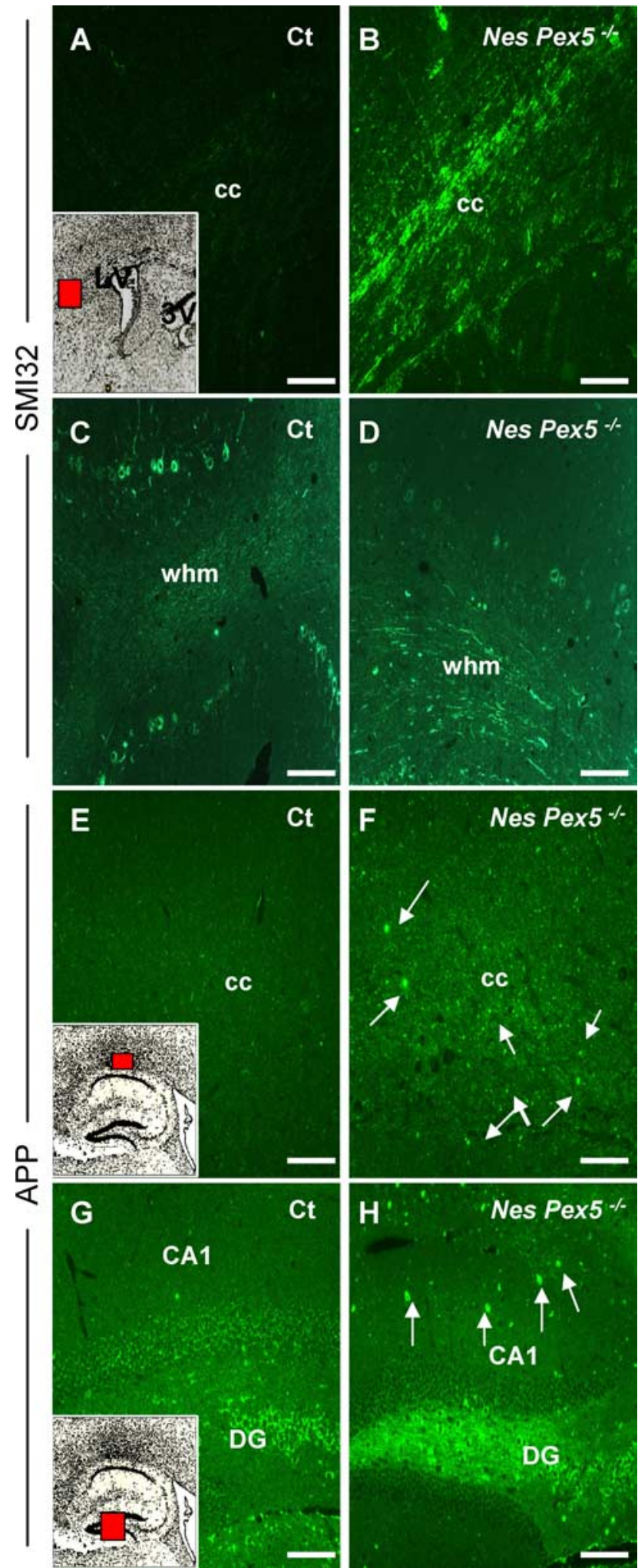

Figure 8. Axonal damage and cell degeneration in the CNS of Nes-Pex5 knock-out mice. $\boldsymbol{A}-\boldsymbol{D}$, Coronal sections of corpus callosum (cc) $(\boldsymbol{A}, \boldsymbol{B})$ and sagittal sections of cerebellum $(\boldsymbol{C}, \boldsymbol{D})$ were stained with SMI32 antibody to detect unphosphorylated neurofilament, a sign of axonal damage, in 5-month-old mice. Strongly enhanced staining was observed in Nes-Pex5 knock-out mice $(\boldsymbol{B}, \boldsymbol{D})$ compared with control mice $(\boldsymbol{A}, \boldsymbol{C})$. This was further confirmed by increased APP immunostaining on sagittal brain sections in the corpus callosum $(\boldsymbol{F})$ and in the hippocampus $(\boldsymbol{H})$ of 5-month-old knock-out mice in comparison with respective areas in control mice $(\boldsymbol{E}, \boldsymbol{G})$. The red squares in the insets in $\boldsymbol{A}, \boldsymbol{E}$, and $\boldsymbol{G}$ indicate in which region of the brain pictures are taken, and arrows point to immunopositive cells in Nes-Pex5 knock-out mice. CA1, Cornu ammonis 1; DG, dentate gyrus; whm, white matter. Scale bars, $100 \mu \mathrm{m}$. disease and a faster disease progression with much shorter lifespan in Nes-Pex5 compared with CNP-Pex5 knock-out mice. This might indicate that peroxisomes in other cell types of the CNS play also a crucial role in the formation and stability of myelinated axons. However, the severe pathology in $C N P$-Pex 5 knock-out mice proves that peroxisomes in oligodendrocytes are essential for the maintenance of myelinated axons. To clarify the precise pathogenesis, additional cell type-selective knock-out mice with elimination of functional peroxisomes from either neurons or astrocytes are now urgently needed. Indeed, perinodal astrocytes might be of crucial importance, because nodal regions are heavily affected, and also the contribution of autonomous neuronal effects impairing axon stability need to be defined.

However, it cannot be excluded that the earlier ablation of peroxisomes from oligodendrocytes when using the Nestin promoter as opposed to the CNP promoter also plays a role in the difference in phenotype between the two mouse models. In NesPex5 knock-out mice, functional peroxisomes were absent from the brain at birth (Krysko et al., 2007). In CNP-Pex5 knock-out mice, oligodendrocyte-specific Cre expression and Pex5 gene recombination in brain was shown in 7-d-old mice (Kassmann et al., 2007). This is before the major wave of myelination but it is not impossible that the already formed etherlipids can stay in the CNS for several days.

In patients with peroxisomal disorders, axonopathies have been reported in the peripheral nervous system and in the spinal cord but no information is available on the brain, probably related to the very few ultrastructural analyses that have been done. Interestingly, adrenomyeloneuropathy, caused by a defect in the peroxisomal transporter $\mathrm{ABCD} 1$, is postulated to be a fundamental defect in the axonal or neuronal membrane, which leads to degeneration but not to apoptotic cell death (Powers et al., 2000, 2001). Also in a mouse model with ABCD1 deficiency, it was demonstrated that axonal damage occurs as first pathological event followed by myelin degeneration (Pujol et al., 2004).

\section{Regional differences in pathologies}

The diverse lesions in Nes-Pex5 knock-out mice show regional differences in severity that are not always linked to the distribution of peroxisomes. The areas with the most distinct lipid accumulations (ependymal cells and molecular layer of cerebellum) maintain high levels of peroxisomes in postnatal life (Ahlemeyer et al., 2007) but do not seem to be hit by the other pathologies. The cerebral cortex and its main commissural system, and to a lesser degree the cerebellum, are most affected with regard to gliosis and damaged myelinated axons. Although the dysmyelinated areas always exhibit severe microgliosis and a less pronounced astrogliosis, it should be emphasized that glial activation also occurs in gray matter. The sparing of the optic nerve from all pathologies is an enigmatic observation, which remains unexplained. Interestingly, in CNP-Pex5 knock-out mice, a similar pattern of lesions was observed whereby white matter abnormalities and axonal swellings first occurred in the genu of corpus callosum extending to fimbriae and anterior commissure, whereas other white matter tracts remained intact (Kassmann et al., 2007).

\section{Pathogenesis of motoric and cognitive impairment}

What is the pathological basis of the progressive loss of motoric and cognitive abilities of Nes-Pex5 knock-out mice? It is quite striking that the phenotypic appearance and course of life of NesPex5 is very similar to that of MFP-2 knock-out mice with impaired peroxisomal $\beta$-oxidation. Indeed, they both develop abnormal reflexes of the paws on lifting, impaired coordination, 

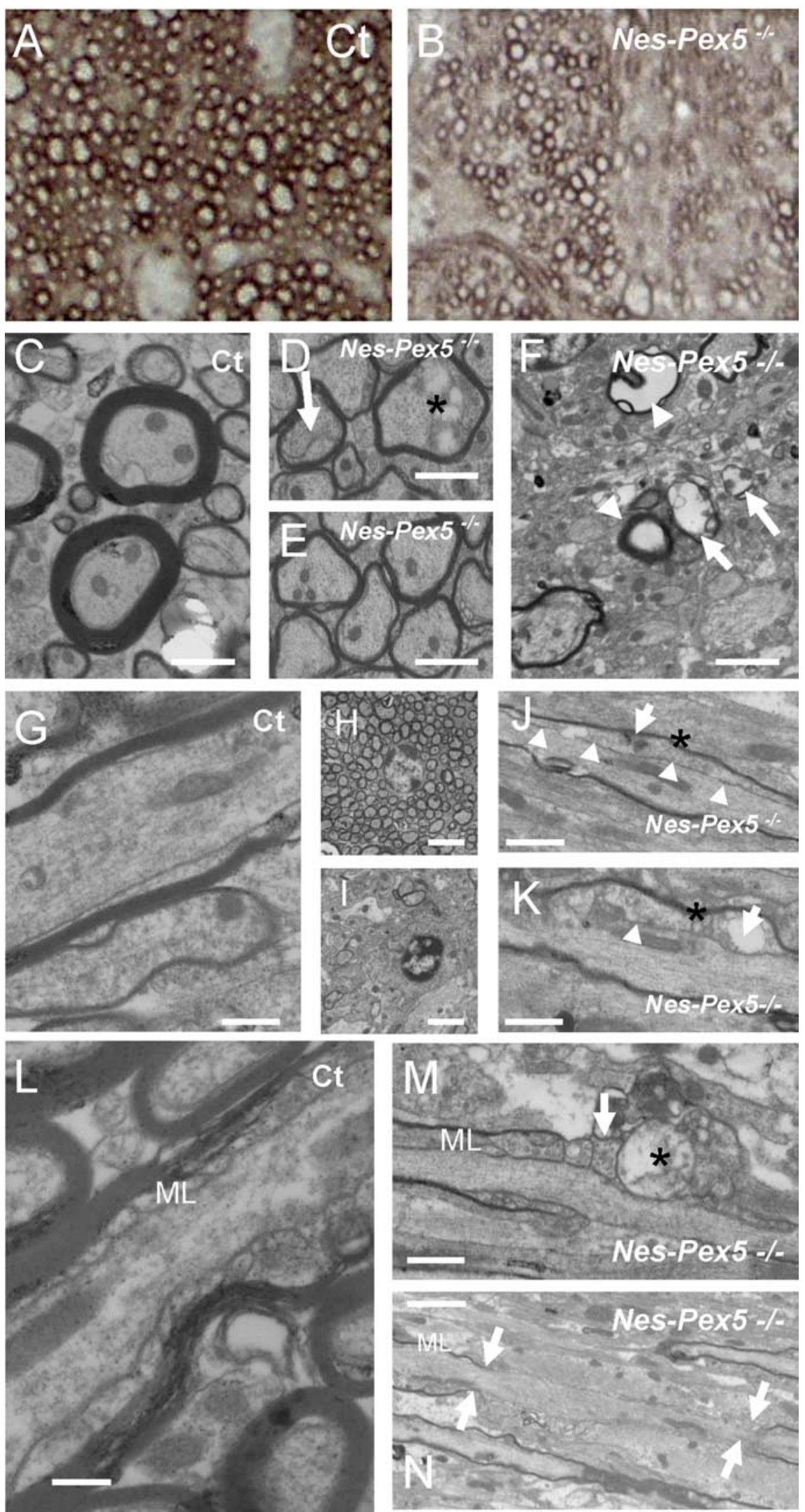

Figure 9. Semithin and ultrastructural analysis of myelin and axon lesions in Nes-Pex5 knock-out mice. $\boldsymbol{A}, \boldsymbol{B}$, Sagittally oriented semithin cross sections of the corpus callosum of 5 -month-old animals stained with $p$-phenylenediamine show a clear reduction of overall stainability of white matter in Pex5-deficient mice. $C-E$, On the ultrastructural level, Nes-Pex 5 knock-out mice contain a majority of structurally almost normal appearing myelinated axons $(\boldsymbol{D}, \boldsymbol{E})$, albeit the thickness of the myelin sheet was often reduced compared with controls $(\boldsymbol{C})$. Note the detachment of an axon from the inner myelin lamella $(\boldsymbol{D}$, arrow) and the accumulation of multivesicular material in a pathological space between axon and inner myelin sheath surface $(\boldsymbol{D}$, asterisk). In a progressive motoric inability, lethargy, and death before the age of 6 months (Huyghe et al., 2006b). We found no evidence for neuromuscular abnormalities in either mouse model. In the brain, Nes-Pex5 and MFP-2 knock-out mice share lipid accumulations, astrogliosis and microgliosis in the gray matter, and increased expression of catalase (Huyghe et al., 2006b).

However, the developmental and sustained myelin abnormalities that were accompanied with massive microgliosis in the corpus callosum and cerebellar white matter were only seen in Nes-Pex5 and did not occur in MFP-2 knock-outs. New observations in MFP-2 knock-out brains revealed extensive axonal damage at different ages (L. Hulshagen, unpublished observations). We therefore propose that axonal damage and/or abnormalities in gray matter that are common between Nes-Pex5 and MFP-2 knock-out mice, rather than dysmyelination, are responsible for the behavioral problems and early death of both mouse models. The present data support the conclusion that peroxisomes are indispensable organelles for the integrity of the CNS, for normal motoric activity and cognitive abilities. Additional investigations are required to pinpoint the essential peroxisomal metabolic conversions and the cell types in which they occur in the CNS.

\section{References}

Adamo AM, Aloise PA, Pasquini JM (1986) A possible relationship between concentration of microperoxisomes and myelination. Int J Dev Neurosci 4:513-517.

Ahlemeyer B, Neubert I, Kovacs WJ, BaumgartVogt E (2007) Differential expression of peroxisomal matrix and membrane proteins during postnatal development of mouse brain. J Comp Neurol 505:1-17.

Arnold G, Holtzman E (1978) Microperoxisomes

$\leftarrow$

6-month-old mouse $(\boldsymbol{F})$, more prominent axonal damage and even complete destruction of axon segments (arrowheads) were seen in still preserved myelin sheaths, whereas in the immediate neighborhood, also a "co-destruction" of axon with their myelin sheaths (arrows) was observed. These features of axonal detachment and collapse were confirmed on longitudinal sections through axons in the corpus callosum ( $G$, $J-\boldsymbol{N})$. In the periaxonal space, degenerated mitochondria and debris accumulated in a segmental manner ( $\boldsymbol{J}, \boldsymbol{K}$, arrows). At the nodes of Ranvier, the exposed myelin-free nodal region was often enlarged ( $\boldsymbol{L} ; \boldsymbol{N}$, arrows), whereas the decompact myelin loops $(\boldsymbol{L}-\boldsymbol{N}, \mathrm{ML})$ were irregularly swollen. Note also significant accumulation of cellular debris in the nodal region ( $M$, asterisk) that could represent degenerated perinodal astrocytes. It is striking thereby that oligodendrocyte cell bodies ( $\boldsymbol{H}, \mathrm{WT} ; \boldsymbol{I}$, Nes-Pex $5^{-1-}$; both shown at 5 months of age) remain normal, without, for example, degenerative changes in the cytoplasm. Scale bars: $\boldsymbol{A}, \boldsymbol{B}, 20 \mu \mathrm{m} ; \boldsymbol{C}-\boldsymbol{E}, 2 \mu \mathrm{m} ; \boldsymbol{F}, 5 \mu \mathrm{m}$; $\mathbf{G}, 1 \mu \mathrm{m} ; \boldsymbol{H}, \mathbf{I}, 5 \mu \mathrm{m} ; \boldsymbol{J}, \boldsymbol{K}, 2 \mu \mathrm{m} ; \boldsymbol{L}, 0.5 \mu \mathrm{m} ; \boldsymbol{M}, \mathbf{N}, 2 \mu \mathrm{m}$. 
in the central nervous system of the postnatal rat. Brain Res 155:1-17.

Baes M, Van Veldhoven PP (2006) Generalised and conditional inactivation of Pex genes in mice. Biochim Biophys Acta 1763:1785-1793.

Baes M, Gressens P, Baumgart E, Carmeliet P, Casteels M, Fransen M, Evrard P, Fahimi D, Declercq PE, Collen D, Van Veldhoven PP, Mannaerts GP (1997) A mouse model for Zellweger syndrome. Nat Genet 17:49-57.

Baes M, Dewerchin M, Janssen A, Collen D, Carmeliet P (2002) Generation of Pex5-IoxP mice allowing the conditional elimination of peroxisomes. Genesis 32:177-178.

Bams-Mengerink AM, Majoie CB, Duran M, Wanders RJ, Van HJ, Scheurer CD, Barth PG, Poll-The BT (2006) MRI of the brain and cervical spinal cord in rhizomelic chondrodysplasia punctata. Neurology 66:798-803.

Biardi L, Krisans SK (1997) Compartmentalization of cholesterol biosynthesis. J Biol Chem 271:1784-1788.

Caeyenberghs K, Balschun D, Roces DP, Schwake M, Saftig P, D'Hooge R (2006) Multivariate neurocognitive and emotional profile of a mannosidosis murine model for therapy assessment. Neurobiol Dis 23:422-432.

DeBruin L, Harauz G (2007) White matter rafting - membrane microdomains in myelin. Neurochem Res 32:213-228.

D’Hooge R, Van Dam D, Franck F, Gieselmann V, De Deyn PP (2001) Hyperactivity, neuromotor defects, and impaired learning and memory in a mouse model for metachromatic leukodystrophy. Brain Res 907:35-43.

Evrard P, Caviness VS, Prats-Vinas J, Lyon G (1978) The mechanism of arrest of neuronal migration in the Zellweger malformation: an hypothesis based upon cytoarchitectonic analysis. Acta Neuropathol 41:109-117.

Ferdinandusse S, Denis S, Mooyer PAW, Dekker C, Duran M, SooraniLunsing RJ, Boltshauser E, Macaya A, Gärtner J, Majoie CBLM, Barth PG, Wanders RJA, Poll-The BT (2006) Clinical and biochemical spectrum of D-bifunctional protein deficiency. Ann Neurol 59:92-104.

Foulon V, Sniekers M, Huysmans E, Asselberghs S, Mahieu V, Mannaerts GP, Van Veldhoven PP, Casteels M (2005) Breakdown of 2-hydroxylated straight chain fatty acids via peroxisomal 2-hydroxyphytanoyl-CoA lyase. J Biol Chem 280:9802-9812.

Ge Y, Belcher SM, Pierce DR, Light KE (2004) Detection of Purkinje cell loss following drug exposures to developing rat pups using reverse transcriptase-polymerase chain reaction (RT-PCR) analysis for calbindin-D28k mRNA expression. Toxicol Lett 150:325-334.

Gielen E, Baron W, Vandeven M, Steels P, Hoekstra D, Ameloot M (2006) Rafts in oligodendrocytes: evidence and structure-function relationship. Glia 54:499-512.

Goddyn H, Leo S, Meert T, D’Hooge R (2006) Differences in behavioural test battery performance between mice with hippocampal and cerebellar lesions. Behav Brain Res 173:138-147.

Gorgas K, Teigler A, Komljenovic D, Just WW (2006) The ether lipiddeficient mouse: tracking down plasmalogen functions. Biochim Biophys Acta 1763:1511-1526.

Gould SJ, Raymond GV, Valle D (2001) The peroxisome biogenesis disorders. In: The metabolic and molecular bases of inherited disease (Scriver CR, Beaudet AL, Valle D, Sly WS, eds), pp 3181-3217. New York: McGraw-Hill.

Holtzman E (1982) Peroxisomes in nervous tissue. Ann NY Acad Sci 386:523-525.

Huyghe S, Casteels M, Janssen A, Meulders L, Mannaerts GP, Declercq PE, Van Veldhoven PP, Baes M (2001) Prenatal and postnatal development of peroxisomal lipid-metabolizing pathways in the mouse. Biochem J 353:673-680.

Huyghe S, Schmalbruch H, De Gendt K, Verhoeven G, Guillou F, Van Veldhoven PP, Baes M (2006a) Peroxisomal multifunctional protein 2 is essential for lipid homeostasis in Sertoli cells and for male fertility in mice. Endocrinology 147:2228-2236.

Huyghe S, Schmalbruch H, Hulshagen L, Van Veldhoven PP, Baes M, Hartmann D (2006b) Peroxisomal multifunctional protein-2 deficiency causes motor deficits and glial lesions in the adult CNS. Am J Pathol 168:1321-1334.

Imamura A, Kamei A, Suzuki Y, Orii T, Takashima S (1994) Developmental immunohistochemistry of bifunctional protein in human brain. Brain Res 640:236-239.

Itoh M, Suzuki Y, Takashima S (1999) A novel peroxisomal enzyme, D-3hydroxyacyl-CoA dehydratase/D-3-hydroxyacyl-CoA dehydrogenase bifunctional protein: its expression in the developing human brain. Microsc Res Tech 45:383-388.

Itoh M, Suzuki Y, Akaboshi S, Zhang Z, Miyabara S, Takashima S (2000)
Developmental and pathological expression of peroxisomal enzymes: their relationship of D-bifunctional protein deficiency and Zellweger syndrome. Brain Res 858:40-47.

Kassmann CM, Lappe-Siefke C, Baes M, Brügger B, Mildner A, Werner HB, Natt O, Michaelis T, Prinz M, Frahm J, Nave K-A (2007) Axonal loss and neuroinflammation caused by peroxisome-deficient oligodendrocytes. Nat Genet 39:969-976.

Krysko O, Hulshagen L, Janssen A, Schutz G, Klein R, De Bruycker M, Espeel M, Gressens P, Baes M (2007) Neocortical and cerebellar developmental abnormalities in conditions of selective elimination of peroxisomes from brain or from liver. J Neurosci Res 85:58-72.

Kumar AJ, Kohler W, Kruse B, Naidu S, Bergin A, Edwin D, Moser HW (1995) MR findings in adult-onset adrenoleukodystrophy. AJNR Am J Neuroradiol 16:1227-1237.

Kwik-Uribe CL, Gietzen D, German JB, Golub MS, Keen CL (2000) Chronic marginal iron intakes during early development in mice result in persistent changes in dopamine metabolism and myelin composition. J Nutr 130:2821-2830.

Mannaerts GP, Van Veldhoven PP (1993) Metabolic role of mammalian peroxisomes. In: Peroxisomes: biology and importance in toxicology and medicine (Gibson G, Lake B, eds), pp 19-62. London: Taylor \& Francis.

Pike LJ, Han X, Chung KN, Gross RW (2002) Lipid rafts are enriched in arachidonic acid and plasmenylethanolamine and their composition is independent of caveolin-1 expression: a quantitative electrospray ionization/mass spectrometric analysis. Biochemistry 41:2075-2088.

Powers JM, Moser HW (1998) Peroxisomal disorders: genotype, phenotype, major neuropathologic lesions, and pathogenesis. Brain Pathol 8:101-120.

Powers JM, Kenjarski TP, Moser AB, Moser HW (1999) Cerebellar atrophy in chronic rhizomelic chondrodysplasia punctata: a potential role for phytanic acid and calcium in the death of its Purkinje cells. Acta Neuropathol 98:129-134.

Powers JM, DeCiero DP, Ito M, Moser AB, Moser HW (2000) Adrenomyeloneuropathy: a neuropathologic review featuring its noninflammatory myelopathy. J Neuropathol Exp Neurol 59:89-102.

Powers JM, DeCiero DP, Cox C, Richfield EK, Ito M, Moser AB, Moser HW (2001) The dorsal root ganglia in adrenomyeloneuropathy: neuronal atrophy and abnormal mitochondria. J Neuropathol Exp Neurol 60:493-501.

Pujol A, Ferrer I, Camps C, Metzger E, Hindelang C, Callizot N, Ruiz M, Pampols T, Giros M, Mandel J-L (2004) Functional overlap between ABCD1 (ALD) and ABCD2 (ALDR) transporters: a therapeutic target for X-adrenoleukodystrophy. Hum Mol Genet 13:2997-3006.

Quarles RH (2007) Myelin-associated glycoprotein (MAG): past, present and beyond. J Neurochem 100:1431-1448.

Rodemer C, Thai TP, Brugger B, Kaercher T, Werner H, Nave K-A, Wieland F, Gorgas K, Just WW (2003) Inactivation of ether lipid biosynthesis causes male infertility, defects in eye development and optic nerve hypoplasia in mice. Hum Mol Genet 12:1881-1895.

Sinha K, Karimi-Abdolrezaee S, Velumian AA, Fehlings MG (2005) Functional changes in genetically dysmyelinated spinal cord axons of Shiverer mice: role of juxtaparanodal Kvl family $\mathrm{K}^{+}$channels. J Neurophys 95:1683-1695.

Tronche F, Kellendonk C, Kretz O, Gass P, Anlag K, Orban PC, Bock R, Klein R, Schütz G (1999) Disruption of the glucocorticoid receptor gene in the nervous system results in reduced anxiety. Nat Genet 23:99-103.

Van Veldhoven PP, Swinnen JV, Esquenet M, Verhoeven G (1997) Lipasebased quantitation of triacylglycerols in cellular lipid extracts: requirement for presence of detergent and prior separation by thin-layer chromatography. Lipids 32:1297-1300.

Van Veldhoven PP, Meyhi E, Mannaerts GP (1998) Enzymatic quantitation of cholesterol esters in lipid extracts. Anal Biochem 258:152-155.

Wanders RJA, Waterham HR (2006) Biochemistry of mammalian peroxisomes revisited. Annu Rev Biochem 75:295-332.

Wanders RJA, Vreken P, Ferdinandusse S, Jansen GA, Waterham HR, Van Roermund CWT, van Grunsven EG (2001) Peroxisomal fatty acid $\alpha$ and $\beta$-oxidation in humans: enzymology, peroxisomal metabolite transporters and peroxisomal diseases. Biochem Soc Trans 29:250-267.

Williard D-E, Harmon SD, Kaduce TL, Preuss M, Moore SA, Robbins MEC, Spector AA (2001) Docosahexaenoic acid synthesis from n-3 polyunsaturated fatty acids in differentiated rat brain astrocytes. J Lipid Res 42: $1368-1376$. 